\title{
Season-dependent predictability and error growth dynamics of Pacific Decadal Oscillation-related sea surface temperature anomalies
}

\author{
Wansuo Duan · Yujie Wu
}

Received: 25 September 2013 / Accepted: 3 October 2014 / Published online: 21 October 2014

(C) The Author(s) 2014. This article is published with open access at Springerlink.com

\begin{abstract}
By performing perfect model predictability experiments in a coupled general circulation model from the point of view of initial error growth, it is demonstrated that there may exist a "summer prediction barrier" (SPB) in the predictions of Pacific Decadal Oscillation-related sea surface temperature anomalies (PDO-related SSTA), which refers to the phenomenon that initial errors exhibit a significant season-dependent evolution, with the largest error growth occurring in the August-September-October (ASO) season. Due to the effect of the SPB, the prediction error of PDO-related SSTA events starts to grow rapidly during the ASO season and yields a positive (negative) prediction error for the warm (cold) events, essentially inducing a delay of the events. The SPB may be one of the main factors limiting the predictability of North Pacific sea surface temperature. The physical and dynamical mechanisms of the SPB are explored from two aspects: thermodynamics and dynamics. In terms of thermodynamics, we demonstrate that the fastest error growth of PDO-related SST cold (warm) events during the ASO season is mainly due to the largest anomalous release (absorption) of the latent heat flux in this season; while for dynamics, the effect of the vertical gradient of climatological mean sea temperature on the anomalous upwelling (downwelling) dominates the contribution of the dynamical temperature
\end{abstract}

W. Duan $(\bowtie) \cdot$ Y. Wu

State Key Laboratory of Numerical Modeling for Atmospheric Sciences and Geophysical Fluid Dynamics (LASG), Institute of Atmospheric Physics, Chinese Academy of Sciences, Beijing 100029, China

e-mail: duanws@lasg.iap.ac.cn

Y. Wu

University of Chinese Academy of Sciences,

Beijing 100049, China advections to the error growth of the PDO-related SST cold (warm) events during the ASO season. The anomalous release (absorption) of the latent heat flux and anomalous upwelling (downwelling) of the ocean currents are both related to the anomalous northwesterly or cyclonic (southeasterly or anticyclonic) wind over the PDO-related SSTA region, which indicates that the error growth associated with the SPB of PDO-related SST cold (warm) events is mainly driven by anomalous wind stress. The error growth associated with the SPB for PDO-related SSTA may also explain why the SSTA in the Kuroshio-Oyashio Extension is much less predictable than in other regions of the North Pacific, as shown by some state-of-the-art climate models.

Keywords North Pacific · Sea surface temperature · Predictability $\cdot$ Error growth

\section{Introduction}

The North Pacific sea surface temperature (NP-SST) and its related atmospheric circulation have broad impacts on weather and climate variability over the North Pacific and surrounding regions, such as North America and East Asia (Lau et al. 2004; Yu and Zhou 2007). One of the most important components of climate variability in the North Pacific is the Pacific Decadal Oscillation (PDO), whose SST signature is characterized by a horseshoe pattern with one sign in the central and western North Pacific, surrounded by anomalies of opposite sign (Latif and Barnett 1994, 1996; Mantua et al. 1997; Zhang et al. 1997). The PDO has a substantial impact on climatic and biological variables (Yatagai and Yasunari 1994; Mantua et al. 1997; Hu et al. 2003; Lau et al. 2004; Yu and Zhou 2007), and thus its successful 
prediction is important in planning and management processes for various stakeholders and policymakers.

Predictions of PDO are related to decadal predictions of NP-SST. The NP-SST variability consists of the effect of complicated interactions of multiple-scale phenomena: the sub-annual timescales dominated by intrinsic North Pacific variability; inter-annual timescales by changes of the Aleutian Low and El Niño-Southern Oscillation (ENSO); and decadal timescales by the ocean circulation anomalies in the Kuroshio-Oyashio Extension (KOE) region, the Aleutian Low and ENSO (Schneider and Cornuelle 2005). Existing numerical models often fail to describe the complicated interaction of these multiple-scale phenomena. Consequently, predictions of NP-SST with long lead times are always of low skill (Schneider and Cornuelle 2005; Newman 2007). Even Schneider and Cornuelle (2005) and Newman (2007) argued that NP-SST may be unpredictable for long lead times due to the effect of complicated interactions of those multiple-scale phenomena mentioned above.

Many scientists estimated the predictability of NP-SST with shorter lead times. In fact, on the seasonal timescale, the evolution of NP-SST also modulates the weather and climate in North America and East Asia (Lau et al. 2004; Hu and Huang 2009; Beattie and Elsberry 2012), and a variety of methods and models have been applied in seasonal predictions of NP-SST (Landman and Mason 2001; Auad et al. 2004; Alexander et al. 2008; Wen et al. 2012). In particular, Wen et al. (2012) investigated the skill of NPSST prediction in a fully coupled ocean-land-atmosphere forecast system [the National Centers for Environmental Prediction (NCEP) Climate Forecast System (Saha et al. 2006)] and demonstrated that the NP-SST, except for the SST over the KOE region, can be predicted with reasonable skill for two-season lead times. This result also indicates that the SST over the KOE region is difficult to predict successfully. Moreover, Alexander et al. (2008) and Auad et al. (2004) showed that the SST forecast skill for lead times longer than one season hardly beats persistence in the KOE region using a linear inverse model and in an uncoupled Pacific Ocean model forced by the fluxes from an uncoupled global atmospheric model, respectively. And Guemas et al. (2012) showed that the bad performances of several state-of-the-art climate models with respect to decadal predictions of NP-SST are due to the failure of the models in representing two major warm SST events in North Pacific, one of which just occurs along the KOE region. It is inferred that the behavior of SST predictability over the KOE region is important for improving the accuracy of not only NP-SST predictions with shorter lead times (e.g., seasonal prediction), but also decadal predictions of NP-SST.

In fact, the KOE is located in a region where the SST signature of the PDO mode is significant [i.e., the region $\left(30^{\circ}-50^{\circ} \mathrm{N}, 145^{\circ} \mathrm{E}-150^{\circ} \mathrm{W}\right)$, marked by the black box in
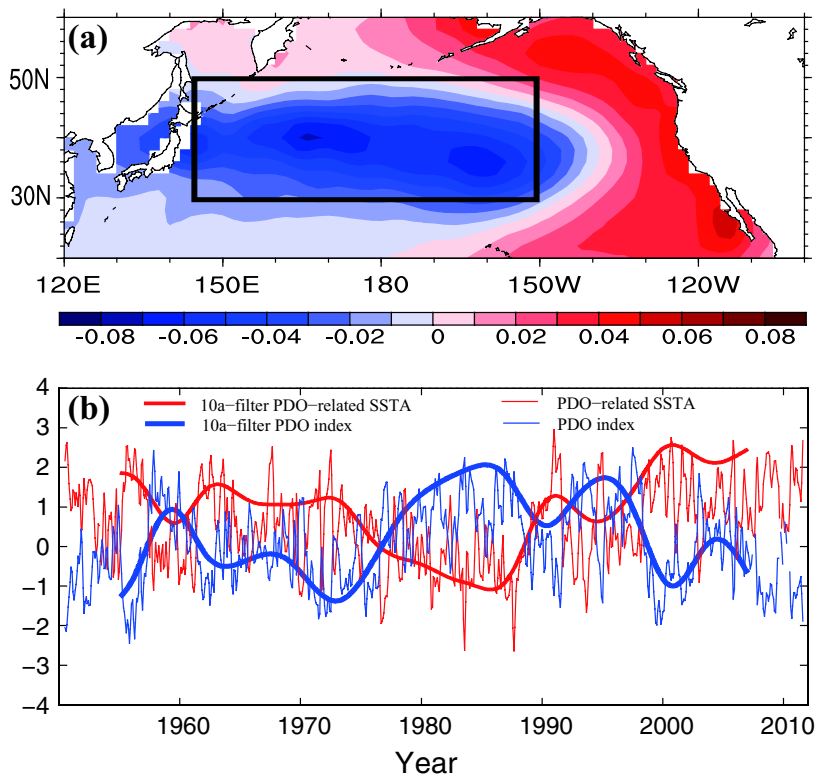

Fig. 1 a The leading EOF mode of North Pacific SSTA, i.e., the PDO mode, derived from 1950 to 2011 ERSST.v3b/NOAA following the method proposed in Mantua et al. (1997); b the corresponding standard monthly PDO index (thin blue line), decadal PDO index (thick blue line), monthly PDO-related SSTA (averaged over the PDOrelated SSTA region; thin red line) and decadal PDO-related SSTA (thick red line)

Fig. 1]. In Fig. 1, it can be seen that the variability of sea surface temperature anomalies (SSTAs) in the black box is highly anti-correlated with that of PDO index, particularly showing a correlation coefficient of $-0.82(-0.71)$ and corresponding explained variance of $65 \%$ (50\%) for monthly (decadal) index (this result is significant at the $95 \%$ confidence level). Therefore, the evolution of these SSTAs captures the variability of PDO mode very well. In this paper, for convenience we denote these SSTAs as "PDO-related SSTA", and the region marked by the black box in Fig. 1 as the "PDO-related SSTA region". We consider that addressing the predictability of PDO-related SSTA is very important in improving the prediction skill of NP-SST, as well as PDO.

Motokawa et al. (2010) demonstrated that the structure of the dominant NP-SST anomaly patterns in boreal summer (especially in August and September) is quite different from those in other seasons, and presents an abrupt change in the evolution of NP-SST anomalies. This indicates that the evolutions of NP-SST anomalies may have their weakest memory when bestriding boreal summer. Actually, Zhao et al. (2012) showed that the SSTA in the central and western Northern Pacific (i.e., the PDO-related SSTA region) has its weakest memory during boreal summer and exhibits a significant "summer persistence barrier", which is a phenomenon that the persistence (autocorrelation) of SSTAs in 
the PDO-related SSTA region shows a significant decline in boreal summer. These results imply that the "summer persistence barrier" may be one of the typical features of the evolution of PDO-related SSTA.

A similar persistence barrier phenomenon has emerged in ENSO-related SSTA, which often exhibits a "spring persistence barrier" (Webster and Yang 1992; Lau and Yang 1996; McPhaden 2003). The effect of the spring persistence barrier on ENSO events also shows itself in numerical predictions of ENSO, exhibiting a "spring prediction barrier". In fact, the spring persistence barrier of ENSO implies the strongest spring dynamical instability of ENSO-related SSTA. The strong instability of the ENSO-related SSTA in spring favors perturbation (i.e., prediction error) growth and may induce loss of forecast skill, ultimately resulting in the spring prediction barrier for ENSO events. Many studies have explored the spring prediction barrier for ENSO events from the point of view of error growth (Lau and Yang 1996; Moore and Kleeman 1996; Samelson and Tziperman 2001), and one of the points that have emerged is that the spring prediction barrier of ENSO relates to the fastest growth of prediction errors during spring. Duan et al. (2009) and Yu et al. (2009) demonstrated that the prediction errors caused by the initial errors are most likely to induce a spring prediction barrier for ENSO events. Furthermore, the prediction errors that are most likely to cause a spring prediction barrier for ENSO tend to possess El Niño- or La Niña-like evolving modes. That is to say, the error growth related to the spring prediction barrier for ENSO events is inclined to follow the same dynamical mechanism as ENSO evolution.

The PDO-related SSTA experiences a similar issue as ENSO in terms of having a persistence barrier, and its predictability could also be explored from the viewpoint of error growth. In this context, we attempt in the present paper to answer the following questions:

1. Do the prediction errors caused by initial errors exhibit their fastest growth during boreal summer and induce a significant summer prediction barrier (SPB) for PDOrelated SSTA? If so,

2. What are the mechanisms of the error growth related to the SPB for PDO-related SSTA?

We explore these questions by analyzing the results of perfect model predictability experiments performed using a coupled global model, and from the point of view of initial error growth. So-called perfect model predictability experiments involve numerical models that are assumed to be perfect, and one only considers the effect of initial errors on the prediction uncertainties (Duan et al. 2009). This approach stems from studies of the first kind of predictability problems proposed by Lorenz (1975).
The remainder of the paper is organized as follows. In Sect. 2, the model, data set and approaches used are described. The season-dependent evolution of the prediction errors for PDO-related SSTA (i.e., the SPB) is reported in Sect. 3. In Sect. 4, we investigate the mechanisms responsible for the SPB of PDO-related SSTA. In Sect. 5, we examine the robustness of the results obtained in Sects. 3 and 4. And finally, a summary of the key findings is presented in Sect. 6.

\section{Model, data set and approach}

The model used in this study is the fully coupled global Fast Ocean Atmosphere Model (FOAM; Jacob 1997), developed jointly at the University of Wisconsin and the Argonne National Laboratory. The atmospheric component (PCCM3-UW), with a horizontal resolution of R15 (equivalent to $7.2^{\circ}$ longitude $\times 4.75^{\circ}$ latitude) and 18 vertical levels, is a parallel version of the National Center for Atmospheric Research (NCAR) Community Climate Model version 2 (CCM2), but with the atmospheric physics replaced by those of CCM3. The oceanic component, with a $z$-coordinate and a resolution of $1.4^{\circ}$ latitude $\times 2.8^{\circ}$ longitude $\times 32$ vertical levels, was developed following the Geophysical Fluid Dynamics Laboratory Modular Ocean Model. Without flux adjustment, the fully coupled model has been integrated for over 1,000 years after a spinup and we find that it does not present any apparent climate drift.

FOAM captures major features of the observed climatology, as in most state-of-the-art climate models (Jacob 1997; Liu et al. 2003). It has been used in addressing a variety of issues of tropical (e.g., Vavrus et al. 2006) and extratropical Pacific climate variability (e.g., Liu and Wu 2004; Yang and Liu 2005). In particular, its performance in simulating the PDO and its related atmospheric and oceanic variables, such as North Pacific SST, wind stress and sea level pressure, is reasonable. Furthermore, the main characteristics (such as period, phase-locking etc.) of FOAM-simulated North Pacific SST are similar to those of observations (see the following paragraph), which therefore provided us with an acceptable platform to perform the perfect model predictability experiments for PDO-related SSTA.

We use version $3 b$ of the National Oceanic and Atmospheric Administration Monthly Extended Reconstructed Sea Surface Temperature Dataset (ERSST.v3b/NOAA) on a $2^{\circ} \times 2^{\circ}$ spatial grid for the period of 1950-2011 (Smith et al. 2008) as the observation to compare with the outputs of FOAM.

It can be seen from Fig. 2a1-a3 that warm and cold SSTAs in the PDO-related SSTA region occur alternately and present an oscillation cycle, with a period of about 2-5 years (see Fig. 3a), similar to that of ENSO. According 

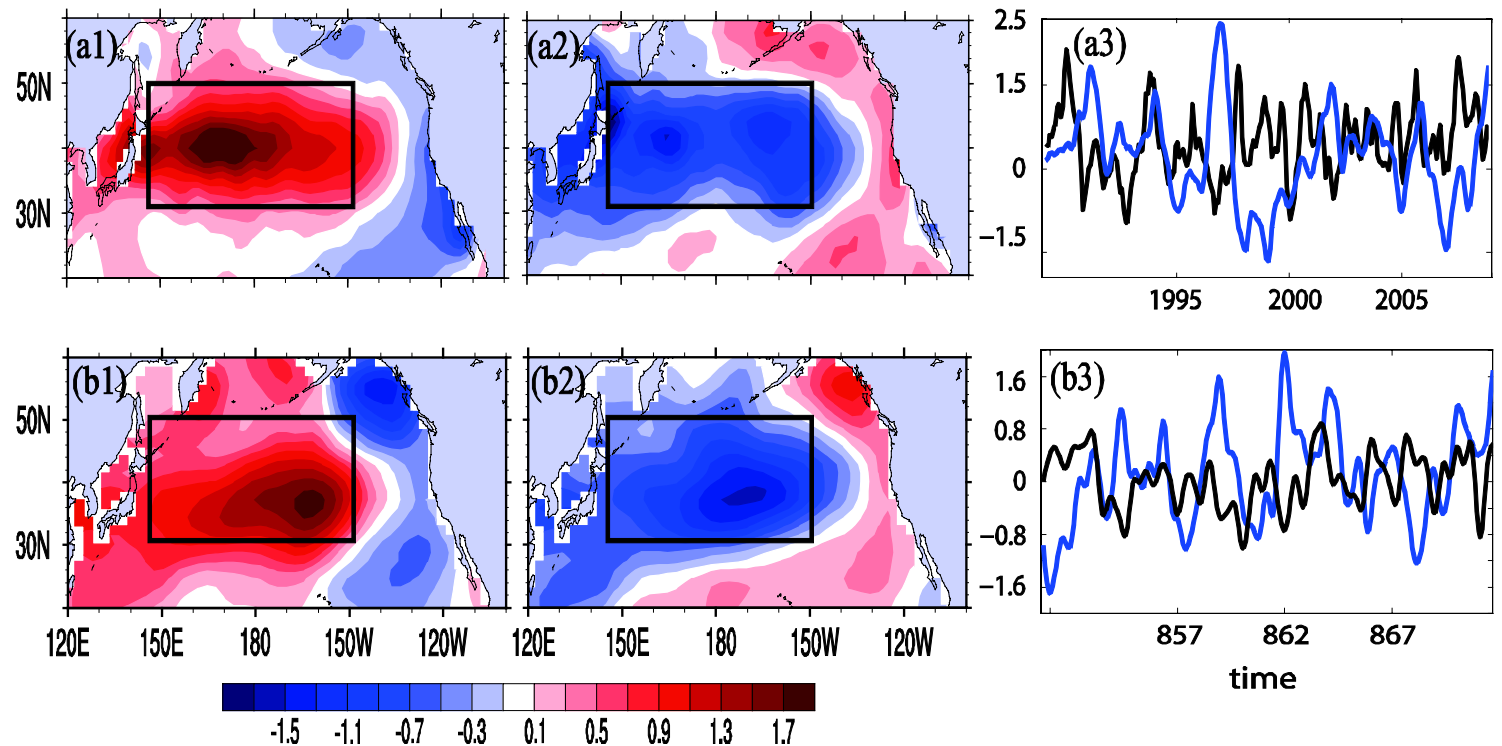

Fig. 2 Composite spatial patterns of the observed NP-SST anomalies in summer (JAS season) for $\mathbf{a} \mathbf{1}$ warm and $\mathbf{a} 2$ cold events during 1950-2011, where the observation is from ERSST.v3b/NOAA; $\mathbf{a} 3$ is the related time series of PDO-related SSTA (black line) and Niño 3.4 index (blue line) during 1990-2010. b1, b2 are the composite spatial patterns of the simulated NP-SST anomalies in summer (JAS season) for warm and cold events from the 1,000-year control run of FOAM. $\mathbf{b 3}$ is the time series of FOAM-simulated PDO-related SSTA (black line) and Niño 3.4 index (blue line) during model years 852-872, which period is randomly selected from the 1,000-year control run and has the same length as in observation in (a3). Units: $\mathrm{K}$
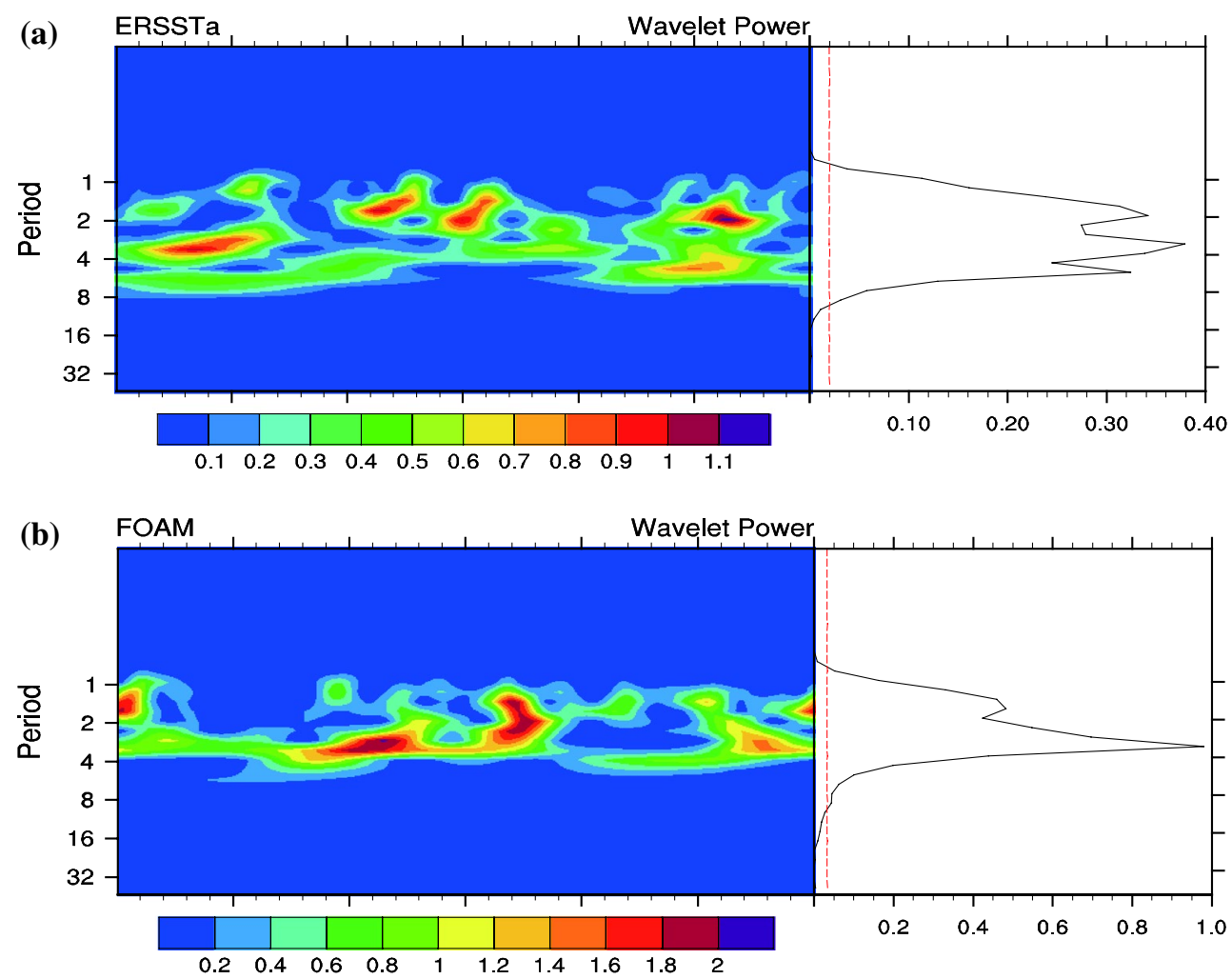

Fig. 3 a The result of wavelet analysis of the time series of 1950-2011 PDO-related SSTA of ERSST.v3b/NOAA; b the result of wavelet analysis of the time series of PDO-related SSTA of the 1,000-year control run in FOAM. The dotted red line represents the $95 \%$ significance 
Table 1 The numbers of observed warm and cold events that tend to peak in the seasons of JFM, AMJ, JAS and OND (statistics derived from SSTA during the period 1924-2011)

\begin{tabular}{lllllllr}
\hline & JFM & AMJ & JAS & OND & Mean duration (months) & Mean amplitude $\left({ }^{\circ} \mathrm{C}\right)$ & Niño 3.4 SSTA $\left({ }^{\circ} \mathrm{C}\right)$ \\
\hline Warm events & 1 & 8 & 13 & 5 & 10.6 & 0.86 & 1.69 \\
Cold events & 1 & 0 & 8 & 2 & 10.8 & -0.76 & -1.50 \\
\hline
\end{tabular}

The mean duration and amplitude in the peak phase of the typical PDO-related SST warm/cold events, and the mean Niño 3.4 index in the peak phase of the ENSO events during 1924-2011 are also shown

Fig. 4 Composite of seasonal evolution of the observed NPSST anomalies for the typical PDO-related SST warm and cold events tending to peak in JAS, where the observation is from ERSST.v3b/NOAA. Units: K
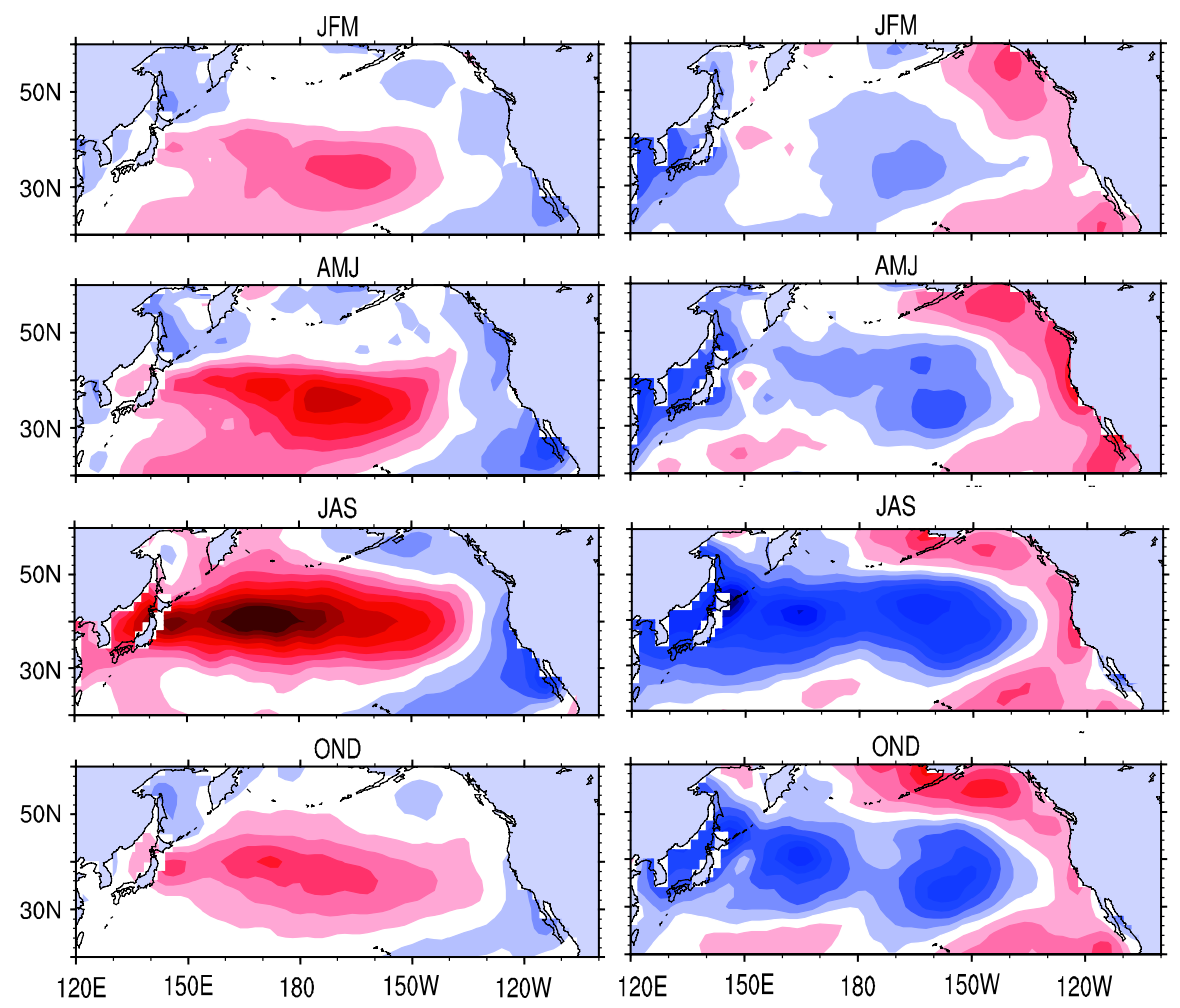

to the NOAA oceanic Niño index (ONI http://www.cpc. ncep.noaa.gov/products/analysis_monitoring/ensostuff/ ensoyears.shtml), if the Niño 3.4 SSTA (or Niño 3.4 index: the 3-month running mean of SSTA averaged over the Niño 3.4 region) larger than $0.5{ }^{\circ} \mathrm{C}$ persists for at least 5 months, it is regarded as an El Niño event. The value of $0.5^{\circ} \mathrm{C}$ is about half of the standard deviation of the Niño 3.4 SSTA. Similarly, we regard half of the standard deviation of the PDO-related SSTA, i.e. $0.25^{\circ} \mathrm{C}$, as one criterion measuring the PDO-related SST warm and cold events. In addition, considering the PDO-related SST warm events are similar to El Niño events and have the duration about 11 months (see Table 1), we define a PDO-related SST warm event if the PDO-related SSTA larger than $0.25{ }^{\circ} \mathrm{C}$ persists for at least 5 months, where the duration is considered as the length of the period ranging from the onset of the event (as soon as the PDO-related SSTA is larger than $0{ }^{\circ} \mathrm{C}$ ) to the death of the event (as soon as the PDO-related SSTA is smaller than $0{ }^{\circ} \mathrm{C}$ ). Conversely, if the PDO-related SSTA smaller than $-0.25{ }^{\circ} \mathrm{C}$ persists for at least 5 months, this event is regarded as a PDO-related SST cold event. The SSTAs of these events are usually established in boreal spring and then subsequently grow in amplitude over the central and western North Pacific, reaching their peak in boreal summer. Of course, there also exist some events whose peaks are not in summer. For the warm and cold events with the peaks in summer, particularly in the JulyAugust-September (JAS) season (see Table 1), we regard them as typical PDO-related SST warm and cold events, respectively (see Fig. 4). The typical warm events often have a shorter average duration but a larger amplitude than the cold events and present a amplitude asymmetry similar to ENSO (see Table 1), which, however, is not significant due to the small amplitude difference between the warm 
Fig. 5 Two examples of the chosen typical PDO-related SSTA events: a cold event, and $\mathbf{b}$ a warm event. They tend to peak in July-August. The months marked by bullet points represent the start months of predictions. These predictions have a lead time of 12 months and bestride the period when the PDO-related SSTA experiences the summer persistence barrier. Units: K
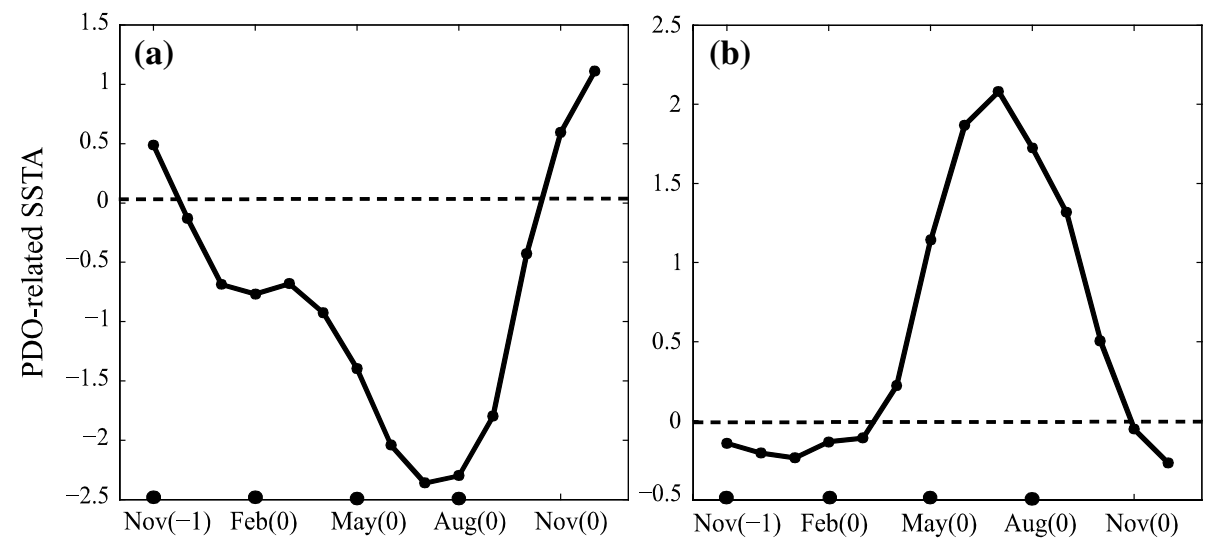

and cold events. In this paper, we focus on these typical PDO-related SST warm and cold events to address the behavior of PDO-related SSTA predictability.

In the perfect model predictability experiments, the model PDO-related SST warm and cold events were regarded as the "true states" (i.e., reference states) to be predicted, and their predictions were obtained by integrating the model with perturbed initial fields. Before the predictions, we integrated a control run with a 1,000-year continuation of the fully coupled simulation after a spinup. In this 1,000-year control run, we obtained a time series of PDO-related SSTA, which was averaged by the SSTA in the PDO-related SSTA region. The model PDO-related SSTA showed a warm-cold cycle with an average period of about 3 years [see Figs. 2b1-b3, 3b]. It should be pointed out that the most significant PDO-related SSTA signal during the peak phase in FOAM is a little eastward of that in the observation, and the model PDO-related SSTA index has smaller amplitude and less frequency noise than the observed one. Despite this, the PDO-related SSTA warmcold cycle in the FOAM presents similar irregular oscillation to the observed one and it can be acceptable for us to investigate the predictability of PDO-related SSTA. In numerical experiments, 20 typical PDO-related SSTA events with different intensities were selected from the control run as the reference states, including 10 warm events and 10 cold ones. Figure 5a, b show one example of a cold and warm event, respectively.

Previous studies have demonstrated that the initial errors causing significant prediction uncertainties for coupled ocean-atmospheric modes (e.g., ENSO events, Kuroshio Large Meander, Atlantic and Pacific blockings, etc.) may have dynamical growth behavior similar to the events themselves (Yu et al. 2009; Jiang and Wang 2010; Duan et al. 2012; Wang et al. 2012a, b). Furthermore, Duan et al. (2009) demonstrated that such kinds of initial errors for ENSO events would be most likely to cause a significant "spring prediction barrier". These results encourage us to investigate the SPB of PDO-related SSTA events by superimposing the initial sea temperature errors derived from PDO-related SSTA. Considering there exists a 1,000year control run of FOAM and we cannot take all sea temperature fields in this long run as initial errors due to expensive time costs in conducting predictability experiments, we applied the EOF (Empirical Orthogonal Function) analysis to the model SSTAs in the North Pacific covering the region $\left(20^{\circ}-60^{\circ} \mathrm{N}, 120^{\circ} \mathrm{E}-100^{\circ} \mathrm{W}\right)$, where the sea temperature anomalies were derived from the 1,000year control run of FOAM. Thus, we were able to obtain the first 20 EOF patterns (denoted as A1-A20, respectively) and their related principal components (PCs). Then, the sea temperature anomalies at the 40,60,80 and $100 \mathrm{~m}$ levels were separately regressed onto the first 20 PCs for the SSTAs to obtain 20 regressed patterns for each level, denoted as B1-B20, C1-C20, D1-D20, and E1-E20, respectively. Each of the first 20 EOFs along with its PCregressed patterns of four different levels composed of one initial error including 5 levels (i.e., $\mathrm{An}, \mathrm{Bn}, \mathrm{Cn}, \mathrm{Dn}$, En; $n=1,2 \ldots 20$ ). Thus, for every PDO-related SST warm or cold event, we had 20 different initial errors to be superimposed on the initial values of the sea temperature field for the reference states. That is to say, for each staring month, the same 20 initial errors were applied for each PDO-related SST warm or cold event to obtain 20 members of predictions. We denoted the initial errors as $T^{\prime}{ }_{0 i j k}$, where $(i, j, k)$ represents the grid points in the region with latitude $i$ ranging from $120^{\circ} \mathrm{E}$ to $100^{\circ} \mathrm{W}$ by $1.48^{\circ}$; longitude $j$ ranging from $20^{\circ} \mathrm{N}$ to $60^{\circ} \mathrm{N}$ by $2.88^{\circ}$; and with vertical levels $k$ being $20,40,60,80$ and $100 \mathrm{~m}$. To investigate the differences among the effects of 20 initial sea temperature errors with different spatial patterns on the prediction errors of PDO-related SSTA events, we scaled the initial errors $T^{\prime}{ }_{0 i j k}$ to have same magnitude by $T_{i j k}^{\prime}=\sigma \cdot T_{0 i j k}^{\prime} /\left\|T_{0 i j k}^{\prime}\right\|$, in which $\left\|T_{0 i j k}^{\prime}\right\|=\sqrt{\sum_{i, j, k}\left(T_{0 i j k}^{\prime}\right)^{2}}$. Then the magnitudes of initial errors are given by $\left\|T_{i j \mathrm{k}}^{\prime}\right\|=\sigma$ despite the variances the corresponding EOFs explained are decreased (for the values of $\sigma$, please refer to as in Sect. 3). 
In this context, we use Year(0) to denote the year when the chosen PDO-related SST warm or cold events attained their peak values, and Year $(-1)$ is the year before Year $(0)$. For each of the predetermined 20 events, we integrated the model for 12 months with 20 initial errors starting from November( $(-1)$ [i.e., November in $\operatorname{Year}(-1)$ ], February $(0)$ [i.e., February in $\operatorname{Year}(0)]$, May(0), and $\operatorname{August}(0)$, respectively (see Fig. 5). Thus, we obtained 80 predictions (20 initial errors $\times 4$ starting months) for every event. The difference between the PDO-related SSTA of reference states $T^{c}(t)$ and their predictions $T^{p}(t)$ is generally referred to as the prediction errors of PDO-related SSTA. In perfect model predictability experiments, the prediction errors are only caused by the growth of initial errors.

To investigate the growth tendency of initial errors, the slope $\kappa=\frac{\partial \gamma(t)}{\partial t}$ of the curve $\gamma(t)=\left\|T^{p}(t)-T^{c}(t)\right\|=\sqrt{\sum_{i, j}\left(T_{i j}^{p}(t)-T_{i j}^{c}(t)\right)^{2}}(i, j)$ represent the latitude and longitude indices in the PDOrelated SSTA region] was computed for a time period, where $\gamma(t)$ measures the magnitude of the prediction error of PDO-related SSTA at the time $t$. In particular, if it is assumed that the prediction error at the start time of the time period $\left[t_{1}, t_{2}\right]$ is of magnitude $\gamma\left(t_{1}\right)$ and at the end of the time period is $\gamma\left(t_{2}\right)$, the growth tendency of the prediction error for the time period $\left[t_{1}, t_{2}\right]$ can be roughly estimated by evaluating $\kappa \approx \frac{\gamma\left(t_{2}\right)-\gamma\left(t_{1}\right)}{t_{2}-t_{1}}$ if the time interval length is sufficient small. In this study, we consider the growth tendencies of prediction errors from one month to next month. Then we will compute 11 growth tendencies of prediction errors in a year. For each growth tendency, it corresponds to a time period, i.e., the period from one month to next month. Since the time periods that the 11 growth tendencies correspond to have a common time interval length, we simply use the values of $\kappa \approx \gamma\left(t_{2}\right)-\gamma\left(t_{1}\right)$ to indicate the growth tendencies. A positive value of $\kappa$ corresponds to an increase of the PDO-related SSTA prediction errors, while a negative value corresponds to a decrease; and the larger the absolute value of $\kappa$, the faster the increase or decrease.

\section{The season-dependent evolution of initial errors for PDO-related SSTA events}

Using the results obtained via the approach described above, in this section we examine the season-dependent evolution of the initial errors associated with PDO-related SST warm and cold events. In the numerical experiments, the 20 chosen events were all predicted for 12 months, each with the same 20 initial errors starting from November( $(-1)$, February(0), May(0), and August( 0$)$, respectively. The magnitude of the initial errors was constrained by $\sigma=5$, i.e., $\left\|T_{i j \mathrm{k}}^{\prime}\right\|=5$, which guaranteed that the magnitude of initial errors was about 30-50\% of initial anomalies of the PDO-related SSTA events, and in this case the absolute value of initial error at each grid point is about $0.2 \mathrm{~K}$ on average. A total of 400 predictions ( 20 events $\times 20$ initial errors) and their related prediction errors were obtained for each of the four starting months, including 200 for warm events and 200 for cold events. According to the method mentioned in the Sect. 2, the growth tendencies of prediction errors were then estimated based on the mean of the 200 prediction errors for warm and cold events. Since the data of the model outputs are monthly means, the growth tendencies $\kappa \approx \gamma\left(t_{2}\right)-\gamma\left(t_{1}\right)$ were evaluated during two continuous months, which guarantees the error growth during these two continuous months is quasi-linear (see Sect. 2). The results show that, no matter what the starting month is, both warm and cold events tend to have significant error growth in the periods from August to September and/or from September to October (this result is significant at the $95 \%$ confidence level); and the total growth of the prediction errors is much larger in the August-September-October (ASO) season, compared to those in other seasons (see Figs. 6, 7). Here, the total growth of prediction errors in a season is measured by the sum of the growth tendencies of prediction errors in the season. For example, the total growth of prediction errors in the ASO season is described by the sum of the growth tendencies of prediction errors in the periods from August to September and from September to October.

Figures 6 and 7 respectively show the total growth (black bars) of prediction errors in each season for the PDO-related SST cold and warm events. The time-dependent evolutions of all prediction errors (color lines) are also shown in Figs. 6 and 7. From these two figures, it is shown that the total growth of prediction errors during ASO are always positive and often have much larger value compared to those during the other seasons (this result is significant at the $95 \%$ confidence level). Therefore, the prediction errors have significant growth during the ASO season, which corresponds to the season when the observed PDO-related SSTA experiences the summer persistence barrier phenomenon, causing a dramatic decrease in the forecast skill during this season. As mentioned in the introduction, predictions of ENSO events tend to yield a significant spring prediction barrier due to significant error growth during spring when the ENSO-related SSTA tends to experience a persistence barrier phenomenon (Mu et al. 2007a; Duan et al. 2009). For the PDO-related SSTA events, the results are clearly similar. That is, a significant error growth occurs during the ASO season when the PDO-related SSTA tends to experience a summer persistence barrier phenomenon. We therefore refer to the phenomenon that the prediction 

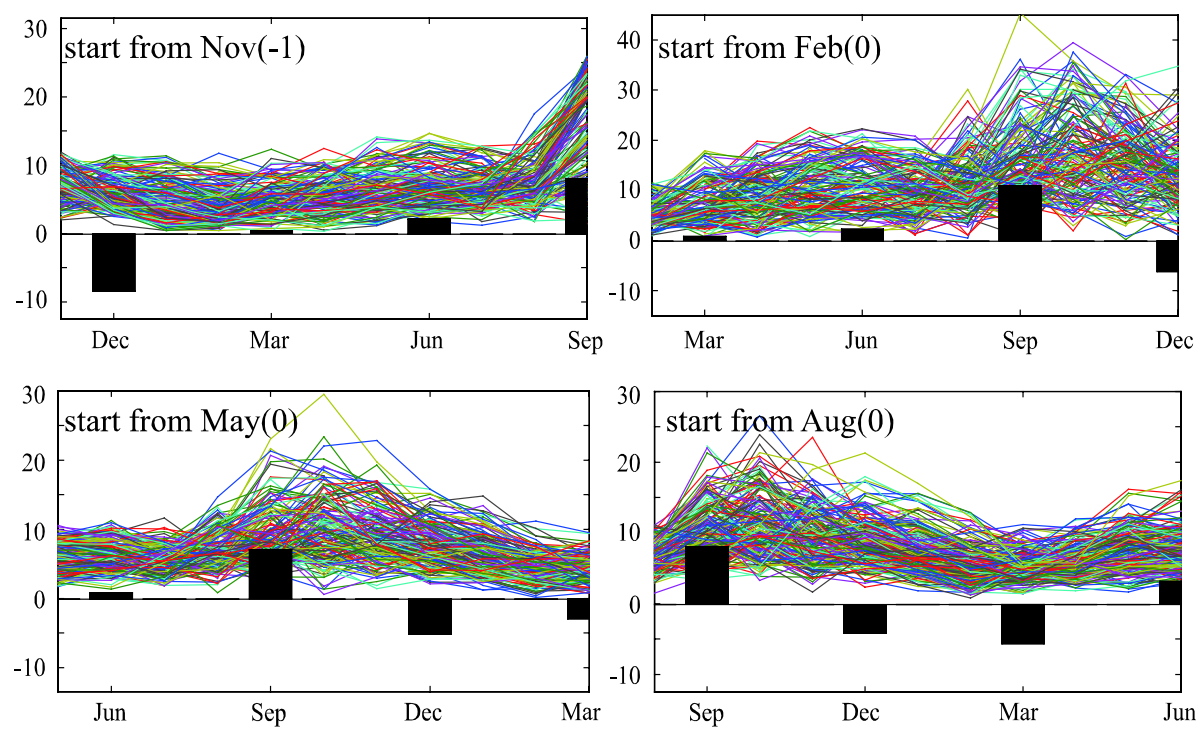

Fig. 6 The time-dependent evolutions (color lines; each line corresponds to one initial error) of the prediction errors in terms of $\gamma(t)$ for the PDO-related SST cold events and the total growth of prediction errors in different seasons including Feb-Mar-Apr, May-JunJul, Aug-Sep-Oct, and Nov-Dec-Jan. The total growth of prediction errors in different season are denoted by the black bars corresponding to Mar, Jun, Sep, Dec in horizontal axis, which are obtained by taking the ensemble mean of the sum of error growth tendencies in the corresponding seasons for the 200 predictions, with the starting months November(-1), February(0), May(0) and August(0), respectively (also see Sect. 3)
Fig. 7 The same as Fig. 6, but for PDO-related SST warm events
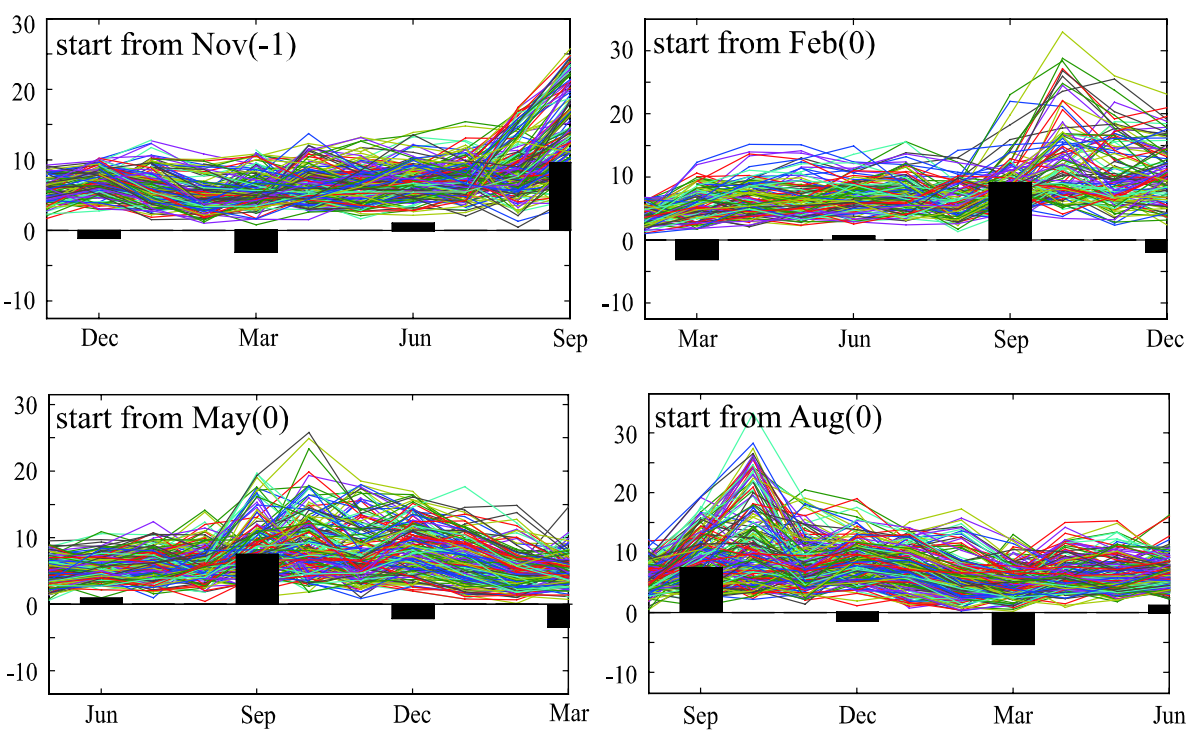

errors exhibit a significant growth during ASO as the "summer prediction barrier" (SPB) of PDO-related SSTA, which means that the forecast skill of PDO-related SSTA may decline dramatically due to the significant growth of prediction errors when the predictions bestride the ASO season. In particular, from Fig. 8 we notice that the predicted PDO-related SST warm (cold) event, due to the effect of initial sea temperature errors, significantly underestimates the reference state event during its growth phase; but during the ASO season, the prediction error starts to grow fast and finally causes the predicted PDO-related SST warm (cold) event to peak at a later time and yield a positive (negative) prediction error at prediction time (exactly after the peak phase of the event). Obviously, the growth of prediction errors in the ASO season, compared to those in other seasons, makes a much larger contribution to the prediction errors at prediction time, which also encourages us to regard the phenomenon of the fast growth of prediction errors during the ASO season as an SPB of PDO-related SSTA. 
Fig. 8 The monthly BoxWhisker Plot of PDO-related SSTA for predetermined a warm events $\mathbf{b}$ cold events and their predictions with the starting month $\mathrm{Feb}(0)$. The black line with black box is for the predetermined PDO-related SSTA events and the blue line with blue box signifies the predictions that occur the SPB. Units: K
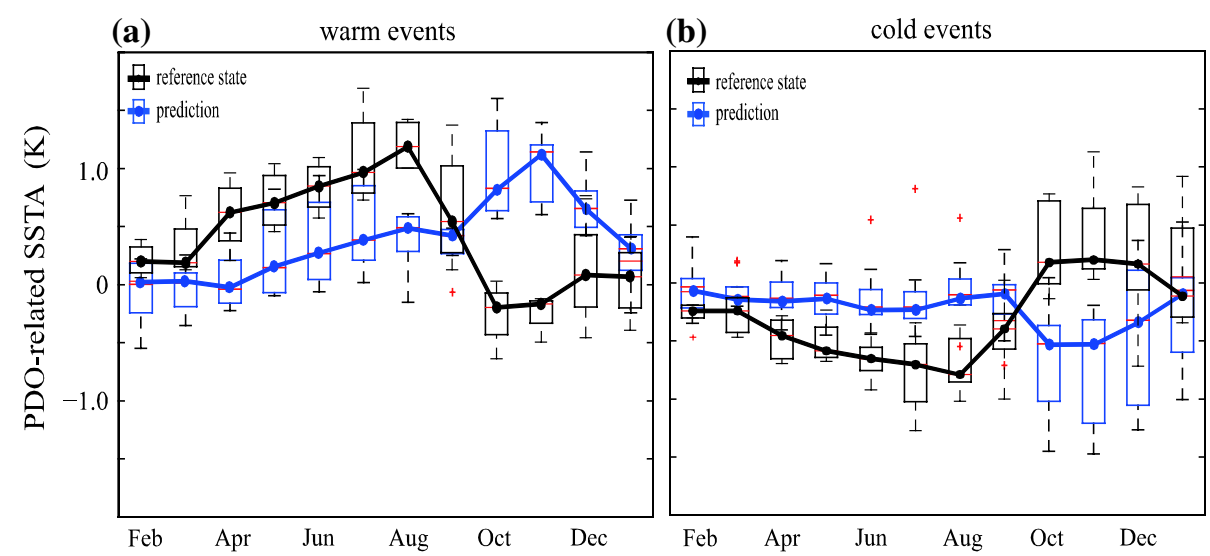

Fig. 9 Ensemble mean of prediction errors in terms of $\gamma(t)$ (see Sect. 2) for a PDOrelated SST warm events and $\mathbf{b}$ PDO-related SST cold events, where the magnitude of prediction errors are estimated by considering the 20 initial errors with $\sigma=0.025$ (dashed line) and $\sigma=5$ (solid line) for each event, respectively. The starting month of the predictions is $\mathrm{Feb}(0)$

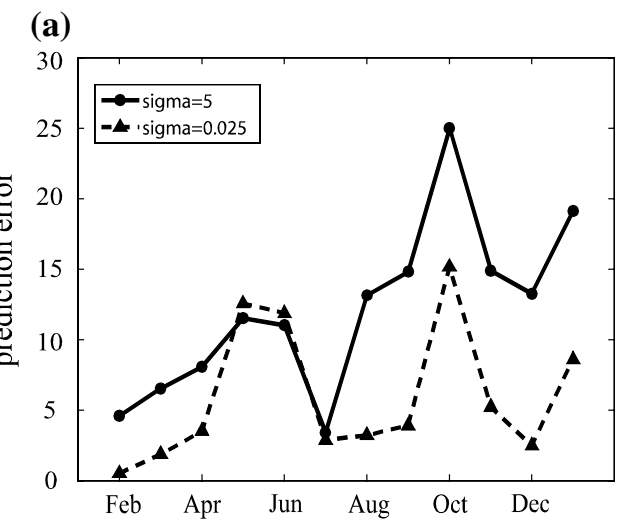

(b)

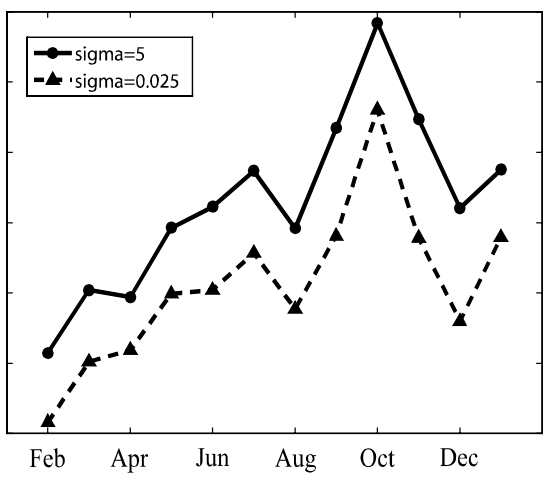

For initial errors with much smaller magnitude of $\sigma=0.025$ (i.e., the absolute value of the initial error at each grid point is about $0.001 \mathrm{~K}$ on average), we also revealed the phenomenon of season-dependent evolution of prediction errors for PDO-related SST warm and cold events, with the largest error growth in the ASO season, but the resultant prediction errors are significantly smaller than those caused by the initial errors with $\sigma=5$ (see Fig. 9). For convenience, we only take the case of $\sigma=5$ as the example to show the mechanism of season-dependent evolution of prediction errors for PDO-related SSTA events.

\section{Possible mechanisms responsible for the error growth associated with the SPB}

In this section, we explain why the PDO-related SSTA tends to yield a significant SPB, within which two questions must be considered: Why do initial errors grow fastest in the ASO season? What is responsible for the physics and dynamics of the error growth associated with the SPB for PDO-related SSTA?

In this study, the SPB of PDO-related SSTA arose from the evolution of prediction errors caused by the initial errors superimposed on the sea temperature anomalies over the North Pacific. Therefore, to address the reason behind the SPB, we focus on the SST equation to trace the related error growth:

$\frac{\partial T}{\partial t}=\frac{Q}{\rho c_{p} \bar{h}}-u \frac{\partial T}{\partial x}-v \frac{\partial T}{\partial y}-w \frac{\partial T}{\partial z}+R$.

The left side of Eq. (1) represents the total tendency of the SST denoted by $T$. The first term of the right side represents the net sea surface heat flux term, where $Q$ describes the net sea surface heat flux, the sum of net latent heat flux, net sensible heat flux, net shortwave radiation flux, and net long-wave radiation flux; and $\rho$ and $c_{p}$ are the density of sea water and the specific heat capacity, respectively. $\bar{h}$ is the climatological monthly mean mixed-layer depth of the 1,000-year control run, which, as shown in observations (Wang et al. 2012a, b), is season-dependent, being deeper in boreal winter and shallower in boreal summer. The second, third and fourth terms are, respectively, the zonal, meridional and vertical oceanic temperature advection terms; and the last term includes the vertical mixing, horizontal mixing and convection, whose contributions to the SST tendency in the extratropics are negligible (Zhang et al. 1998). It should be noted that this equation is only 
an approximation, since we consider a mixed layer heat budget and approximate the SST by the mixed-layer sea temperatures. We use the climatological mixed-layer depth instead of the instantaneous one and consider that all the surface heat flux is absorbed within the mixed layer and not below.

Based on Eq. (1) and the minor roles of vertical mixing, horizontal mixing and convection in the extratropics, the equation governing the evolution of SST prediction errors can be derived as follows:

$$
\begin{aligned}
\frac{\partial T^{\prime}}{\partial t}= & \frac{\partial\left(\bar{T}+T^{*}+T^{\prime}\right)}{\partial t}-\frac{\partial\left(\bar{T}+T^{*}\right)}{\partial t} \\
= & \frac{Q^{\prime}}{\rho c_{p} \bar{h}}+\left(\bar{U}+U^{*}+U^{\prime}\right) \\
& +\left(\bar{V}+V^{*}+V^{\prime}\right)+\left(\bar{W}+W^{*}+W^{\prime}\right),
\end{aligned}
$$

in which,

$$
\begin{aligned}
Q^{\prime} & =\left(\bar{Q}+Q^{*}+Q^{\prime}\right)-\left(\bar{Q}+Q^{*}\right) \\
& =L H^{\prime}+S H^{\prime}+L W H^{\prime}+S W H^{\prime}
\end{aligned}
$$

and

$$
\begin{array}{lll}
\bar{U}=-\bar{u} \frac{\partial T^{\prime}}{\partial x}-u^{\prime} \frac{\partial \bar{T}}{\partial x} & \bar{V}=-\bar{v} \frac{\partial T^{\prime}}{\partial y}-v^{\prime} \frac{\partial \bar{T}}{\partial y} & \bar{W}=-\bar{w} \frac{\partial T^{\prime}}{\partial z}-w^{\prime} \frac{\partial \bar{T}}{\partial z} \\
U^{*}=-u^{*} \frac{\partial T^{\prime}}{\partial x}-u^{\prime} \frac{\partial T^{*}}{\partial x} & V^{*}=-v^{*} \frac{\partial T^{\prime}}{\partial y}-v^{\prime} \frac{\partial T^{*}}{\partial y} & W^{*}=-w^{*} \frac{\partial T^{\prime}}{\partial z}-w^{\prime} \frac{\partial T^{*}}{\partial z} . \\
U^{\prime}=-u^{\prime} \frac{\partial T^{\prime}}{\partial x} & V^{\prime}=-v^{\prime} \frac{\partial T^{\prime}}{\partial y} & W^{\prime}=-w^{\prime} \frac{\partial T^{\prime}}{\partial z}
\end{array}
$$

In Eqs. (2-4), a bar represents the climatological mean state, an asterisk denotes the reference states to be predicted (the predetermined model warm or cold events in this case), and a prime signifies the prediction errors caused by initial errors. As such, Eq. (3) describes the effect of the net sea surface heat flux errors on the growth of the prediction uncertainties of PDO-related SSTA, which is the sum of latent heat flux error $L H^{\prime}$, sensible heat flux error $S H^{\prime}$, shortwave radiation flux error $S W H^{\prime}$, and long-wave radiation flux error $L W H^{\prime}$. A positive $Q^{\prime}$ means an anomalous absorption of the sea surface heat flux, while a negative value means a release. Equation (4) indicates the effect of oceanic temperature advections on the growth of the prediction uncertainties of PDO-related SSTA, where $\bar{U}, \bar{V}$ and $\bar{W}$ represent the effect of climatological zonal, meridional, and vertical temperature advections on the error growth; $U^{*}, V^{*}$ and $W^{*}$ describe the effect of the temperature advections associated with the reference state warm or cold events on the error growth; and $U^{\prime}, V^{\prime}$ and $W^{\prime}$ reflect the effect of nonlinear interactions of temperature advection errors on the error growth of PDO-related SSTA. Here, we should say that Eq. (2) is also an approximation since we consider that the climatological heat flux and the anomalous heat flux has no effect on the prediction error and neglect the potential influence of all the advections cross-terms between climatological and/or anomalous currents and temperature.
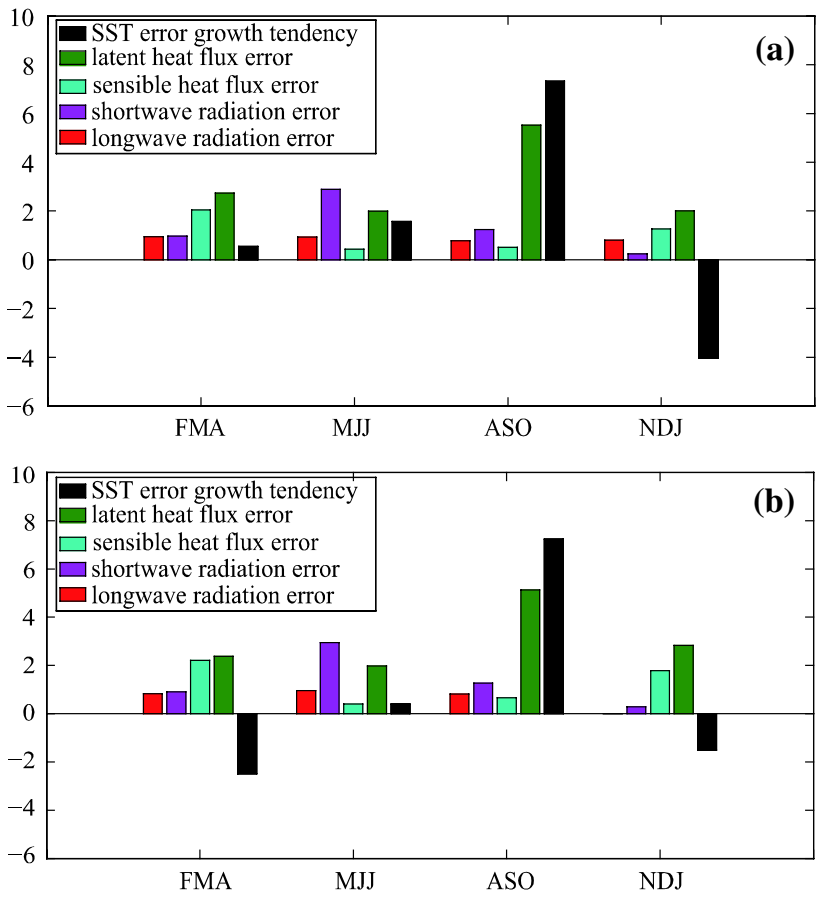

Fig. 10 Error growth tendencies of the PDO-related SST a cold and b warm events in each season (black bars) and the related four flux errors (colored bars; measured by the given norm in Sect. 4.1), which are respectively based on the mean of the 200 predictions for the cold and warm events. The starting month of the predictions is Feb(0). Units: K/month

From Eqs. (2-4), it can be approximately established that the contributions to the error growth of PDO-related SSTA are from two parts: one comes from the thermodynamics denoted by $Q^{\prime}$, and the other is from the dynamics described by Eq. (4). In the following subsections, we explain the possible mechanisms of the error growth associated with the SPB of PDO-related SSTA from these two aspects, i.e., thermodynamics and dynamics.

\subsection{Thermodynamics}

According to Eq. (2), a positive (negative) $Q^{\prime}$ will lead to an amplifying (damping) positive SSTA errors and damping (amplifying) negative SSTA errors. The $Q^{\prime}$ can be divided into four parts including $L H^{\prime}, S H^{\prime}, L W H^{\prime}$ and $S W H^{\prime}$, which, respectively, are the errors superimposed on the latent heat flux, sensible heat flux, shortwave radiation flux, and longwave radiation flux components. In Fig. 10, we plot these four kinds of flux errors associated with PDO-related SSTA, which are estimated by the mean of 200 predictions starting from $\mathrm{Feb}(0)$ and measured by the $\operatorname{norm} H=\sqrt{\sum_{i, j} H_{i j}^{2}} \quad\left[H_{i j}=F l u x_{i j} / \rho c_{p} \bar{h} \quad\right.$ denotes the flux error at each grid point $(i, j)$ in the PDO-related SSTA region; Flux represents $L H^{\prime}, S H^{\prime}, L W H^{\prime}$, or $\left.S W H^{\prime}\right]$. 


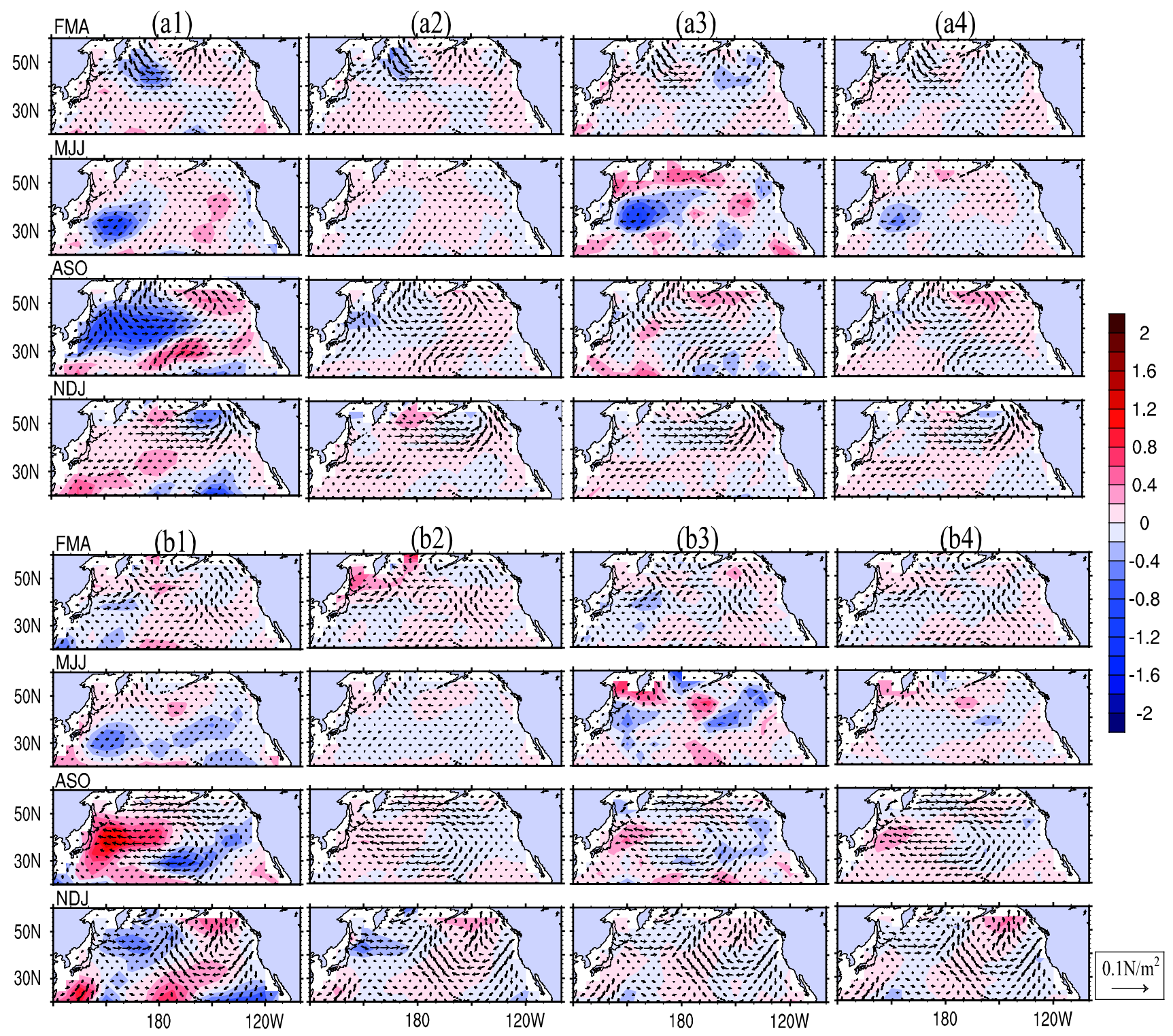

Fig. 11 Composite spatial patterns of four kinds of sea surface heat flux errors (shaded; units: K/month) and the related wind stress errors (vectors; units: $\mathrm{N} / \mathrm{m}^{2}$ ) in the FMA, MJJ, ASO and NDJ seasons for the 200 predictions of warm and cold events, respectively. a1-a4 rep-

It is demonstrated that the evolution of the latent heat flux error $L H^{\prime}$ shows itself to be largest in the ASO season and is significantly larger than the other flux errors. This indicates that the latent heat flux error may dominate the net sea surface heat flux component of the prediction errors for PDO-related SSTA; its growth behavior may describe that of the net sea surface heat flux errors. To further validate this argument, we also investigated the spatial patterns of the four kinds of flux errors in different seasons. We found that, either for the PDO-related SST warm or cold events, the latent heat flux error $L H^{\prime}$, compared to other flux errors, shows an aggressively larger error, especially

resent the errors of the latent heat flux, sensible heat flux, shortwave radiation flux, and longwave radiation flux for cold events, while (b1-b4) are the same as (a1-a4), but for warm events. The starting month of the predictions is $\mathrm{Feb}(0)$

in the PDO-related SSTA region and in the ASO season (see Fig. 11). Also Fig. 11 illustrates an amplification of the PDO-related negative SSTA associated with the cold events by a negative heat flux anomaly and an amplification of the PDO-related positive SSTA for the warm events by a positive heat flux anomaly in the ASO season. Nevertheless, this result does not indicate the predicted PDO-related SST warm and cold events are much stronger. Compared with Fig. 8, it is shown that the error growth associated with the SPB aggressively overestimates the PDO-related SSTA after the peak phase of the events and delays the damping of the events. For other starting months, similar 

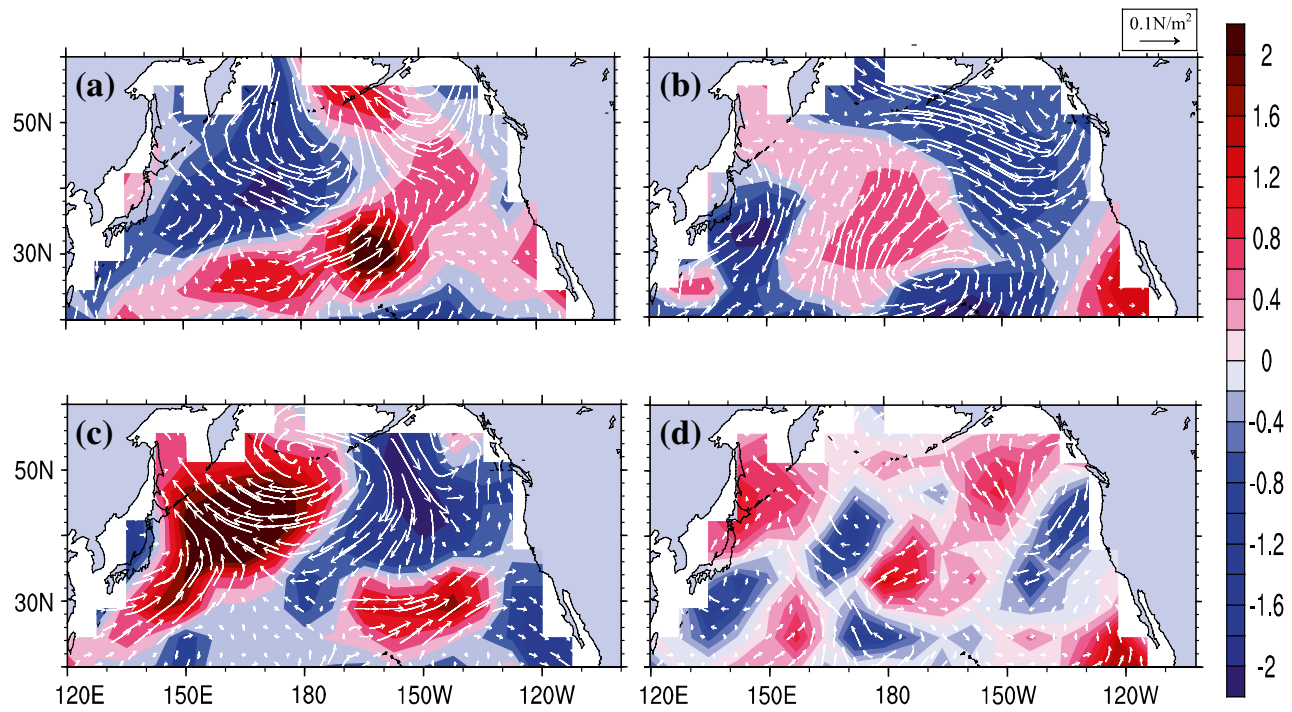

Fig. 12 a Spatial patterns of latent heat flux error corresponding to a prediction error that causes a significant SPB for the cold event in Fig. 5 (shaded; units: K/month) and related wind stress errors (vectors; units: $\mathrm{N} / \mathrm{m}^{2}$ ) in the ASO season. b Spatial patterns of latent heat

results were obtained. Therefore, we are able to show that the errors of the net sea surface heat flux in the ASO season are mainly due to the contribution of latent heat flux error. This suggests that the net latent heat flux error $L H^{\prime}$ may be one of the major error sources leading to the SPB of PDOrelated SSTA-but how does this happen?

To explore this question, we use the bulk formula

$L H_{\uparrow}=\rho_{a} L_{E} C_{E}\left|\vec{v}_{a}\right|\left(q_{s}\left(T_{s}\right)-q_{a}\right)$,

which is usually used to estimate latent heat flux (Cayan 1992a). In Eq. (5), $\rho_{a},\left|\vec{v}_{a}\right|, q_{s}\left(T_{s}\right)$ and $q_{a}$ are the density of the air, wind speed, the saturation specific humidity, and specific humidity; $L_{E}$ is the latent heat of evaporation of water, which is approximately $2.50 \times 10^{6} \mathrm{~J} / \mathrm{kg}$; and $C_{E} \sim 1.2 \times 10^{-3}$ is the transfer coefficient for latent heat. According to Eq. (5), latent heat flux increases with wind speed $\left|\vec{v}_{a}\right|$ and the difference between ocean surface saturation humidity and air humidity, i.e., $\Delta q=q_{s}\left(T_{s}\right)-q_{a}$.

Figure 12a, b show the ASO-season patterns of the latent heat flux and related wind stress components of the prediction errors caused by two initial errors for the cold event shown in Fig. 5a, in which one initial error has the largest growth rate in the ASO season and corresponds to a significant SPB of PDO-related SSTA, while the other one presents a trivial error growth and fails to cause an SPB. We take these two errors as examples to explain how the significant growth of the PDO-related SSTA errors occurs in the ASO season. Figure 12a shows that, for the error that causes a significant SPB of PDO-related SSTA, anomalously strong northwesterly wind arises over the PDOrelated SSTA region, which brings the cold and dry air from

flux error corresponding to a prediction error that fails to cause a significant SPB for the cold event in Fig. 5. c, d are the same as (a) and (b), but for the warm event in Fig. 5

the land to the PDO-related SSTA region and increases the difference between ocean surface saturation humidity and air humidity, ultimately favoring the anomalous release of latent heat flux (Cayan 1992b) and then making the negative PDO-related SSTA much more negative, meaning that a negative prediction error of PDO-related SSTA for the cold event occurs. However, for the error that fails to cause a significant SPB, Fig. 12b demonstrates that significantly anomalous winds over the PDO-related SSTA region do not occur, thus failing to yield a considerable change in latent heat flux and subsequently not causing a large error in this region. Similar results were also obtained for warm events, except that the SPB-related error yields an anomalously strong southeasterly wind over the PDO-related SSTA region and then induces a positive prediction error of PDOrelated SSTA in the ASO season (Fig. 12c). For the case that fails to cause an SPB, the anomalous southeasterly wind over the PDO-related SSTA region is much weaker and does not cause an anomalously significant absorption of the latent heat flux (Fig. 12d), which in turn does not result in a large error growth of PDO-related SSTA in the ASO season. Furthermore, Fig. 12 indicates that not all of the initial errors have significant error growth for the PDOrelated SSTA events in the ASO season. Actually, it is the initial errors causing a significant SPB that lead to a large error growth in the ASO season.

From the above results, it is shown that the largest error growth of the net latent heat flux associated with the PDO-related SSTA during the ASO season is mainly due to the largest anomalous latent heat flux release for the cold events (absorption for the warm events) in this 
(a)

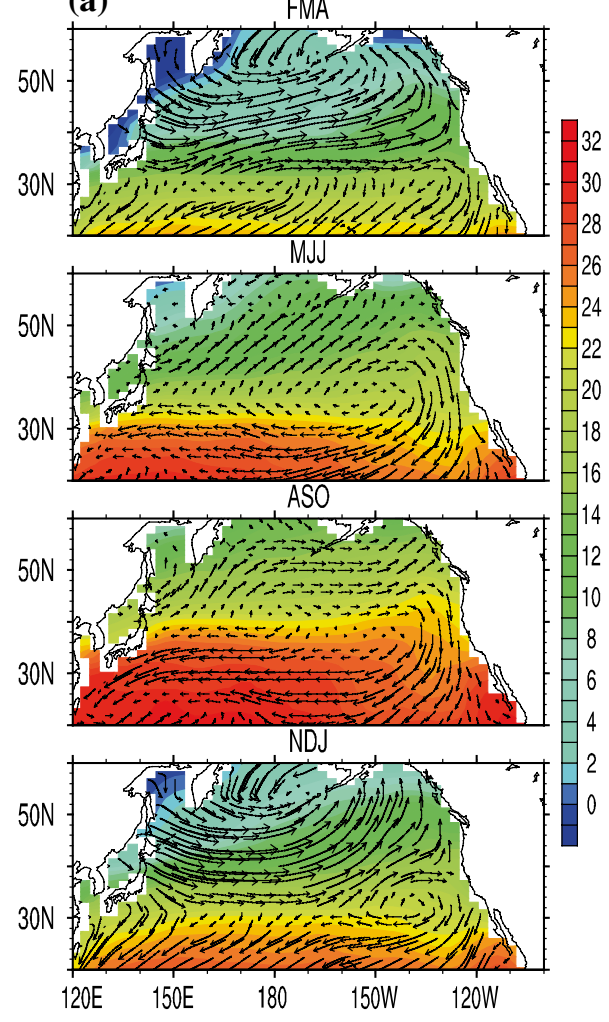

(b)

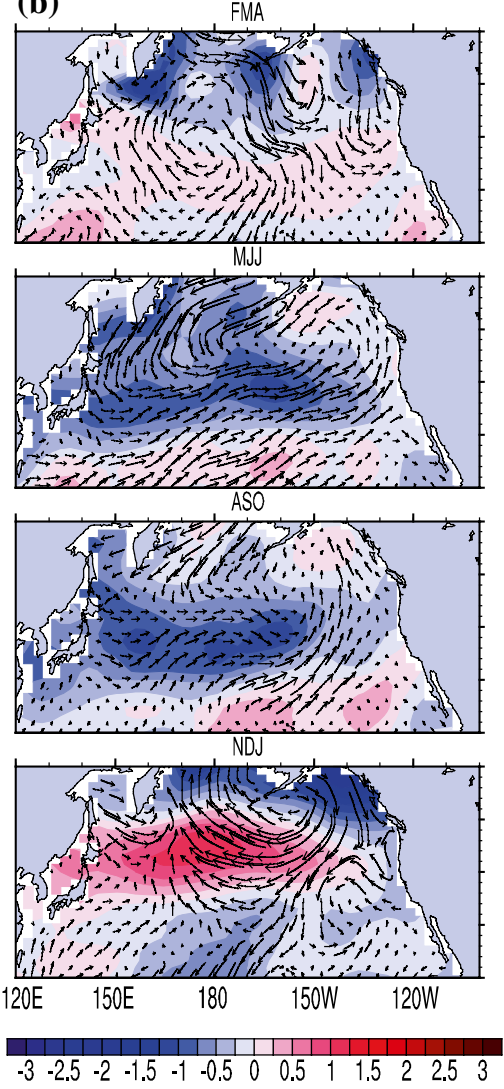

(c)
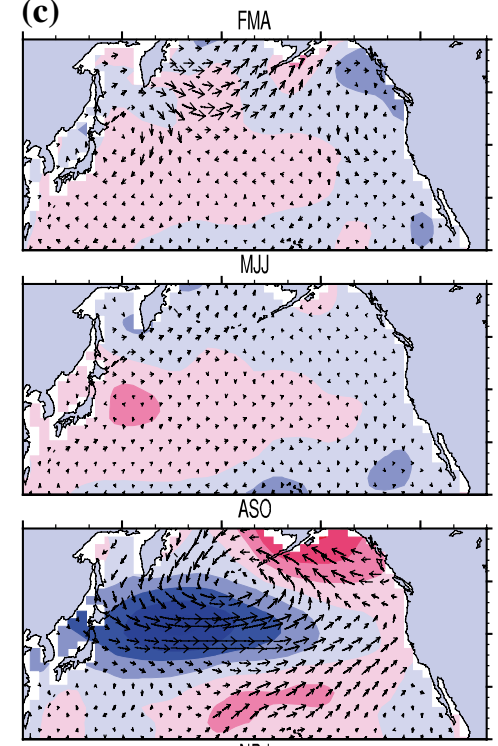

NDJ

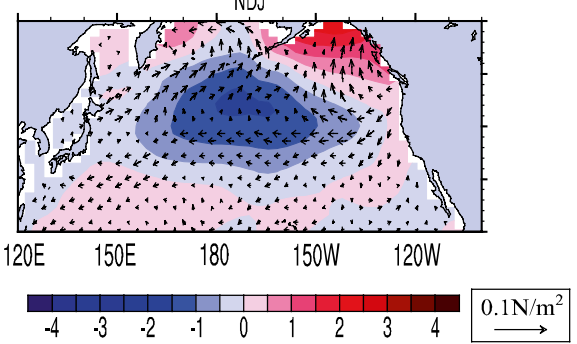

Fig. 13 a The climatological seasonal mean NP-SST (shaded; units: $\mathrm{K}$ ) and its related wind stress (vectors; units: $\mathrm{N} / \mathrm{m}^{2}$ ); $\mathbf{b}$ the composite patterns of NP-SST anomalies (shaded; units: K) and the correspond-

season; and the corresponding anomalous northwesterly (southeasterly) wind stress over the PDO-related SSTA region occurring in the ASO season may provide a possible explanation to the largest anomalous latent heat flux release (absorption), then the largest error growth of the net latent heat flux for PDO-related SSTA events in the ASO season. From Eq. (3), it is inferred that the net latent heat flux error is $L H^{\prime}=\left(L \bar{H}+L H^{*}+L H^{\prime}\right)-\left(L \bar{H}+L H^{*}\right)$, where a bar represents the climatological mean state, an asterisk denotes the reference states to be predicted, and a prime signifies the prediction errors caused by initial errors. Therefore, the error growth of the net latent heat flux may be affected by the climatological mean state and the predetermined PDO-related SST warm or cold events. Naturally, we therefore ask: how do the climatological mean state and the reference state cold and warm events modulate the error growth of the net latent heat flux associated with the SPB of PDO-related SSTA?

The climatological seasonal mean NP-SST and wind stress are illustrated in Fig. 13a. Significant westerly or northwesterly winds are shown to be located over the midlatitudes of the North Pacific from December to April, ing wind stress (vectors; units: $\mathrm{N} / \mathrm{m}^{2}$ ) associated with the 10 predetermined cold events; and $\mathbf{c}$ their related prediction errors

while the winds are much weaker during ASO compared to those during other seasons. Since the large-scale flux-SST tendency connection is driven by the atmospheric circulation (Cayan 1992a), the weak climatological winds in summer indicate the frailty of the North Pacific circulation and then the weak atmospheric forcing effect on the NP-SST (Frankignoul and Sennéchael 2007). The forcing effect of climatological atmospheric winds in summer over the North Pacific basin is not significant enough to constrain the evolution of the PDO-related SSTA errors, which then provides the climatological background that errors grow at their most rapid rate of the year during the ASO season (Webster 1995). Then, in the experiments, why are the prediction errors for cold (warm) events in the ASO season generally negative (positive)? Next, we explore the role of predetermined PDO-related SST warm and cold events in the error growth associated with SPB.

Figure 13b shows the composite of the evolutions of SSTA and related wind stress anomaly for the 10 predetermined PDO-related SST cold events. It is illustrated that, in summer and early autumn, a cyclonic wind stress anomaly occurs in the North Pacific; especially a northwesterly 


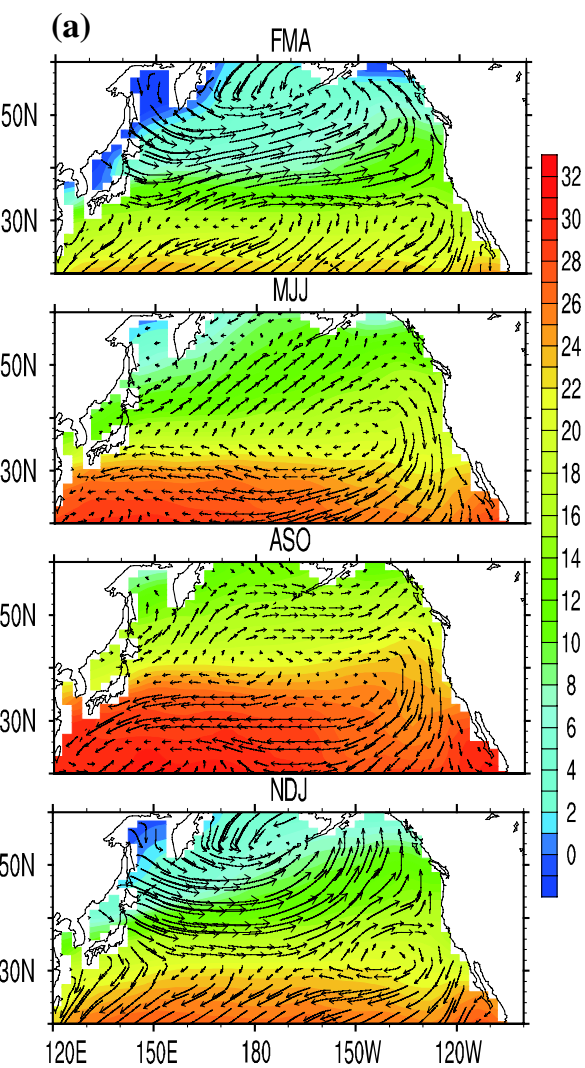

(b)

3
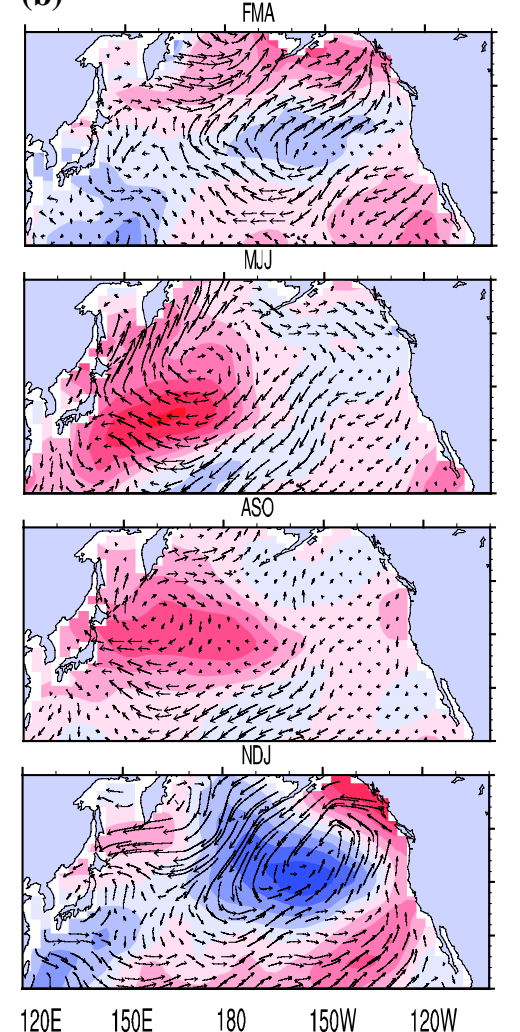

120E $\quad 150 \mathrm{E} \quad 180 \quad 150 \mathrm{~W} \quad$ 120W

$\begin{array}{lllllllllllll}-3 & -2.5 & -2 & -1.5 & -1 & -0.5 & 0 & 0.5 & 1 & 1.5 & 2 & 2.5 & 3\end{array}$ (c)
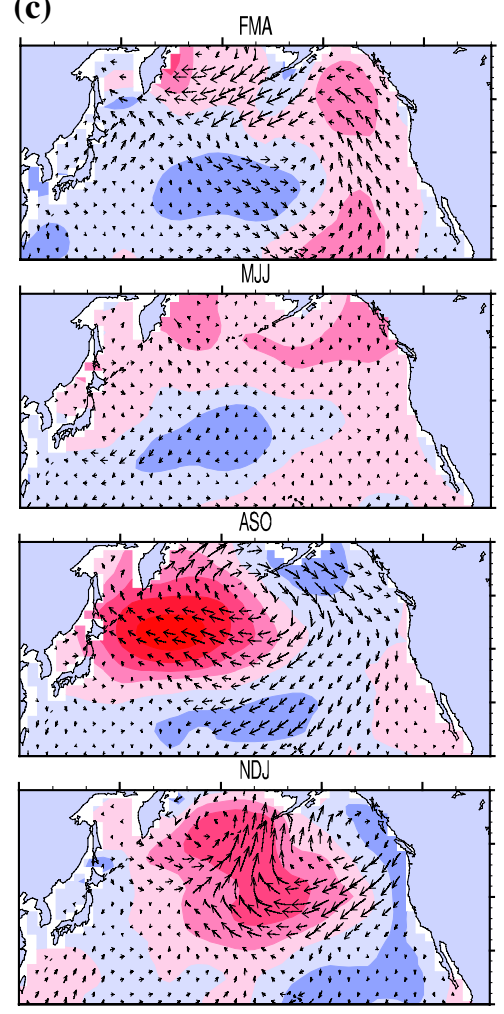

120E 150E 180 150W 120W

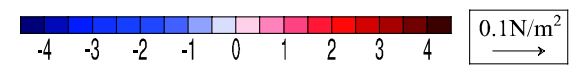

Fig. 14 The same as in Fig. 13, but for the warm events

arises in the south of the cyclonic wind. Furthermore, we notice that the largest wind stress errors are in the ASO season and are also cyclonic (Fig. 13c), which is superimposed onto the cold events-related cyclonic wind stress anomalies and increases the northwesterly occurring in the PDOrelated SSTA region in the ASO season. The increased northwesterly wind brings the cold and dry air from the land to the PDO-related SSTA region and induces more anomalous release of latent heat flux [see Eq. (5); also see Cayan 1992b], ultimately favoring much colder SST for the cold events and making the events to be over-estimated in the ASO season. In addition, a cyclonic wind stress anomaly favors an anomalous upwelling of cold waters dynamically through the Ekman effect. The cyclonic wind errors force the cold events-related cyclonic wind anomalies and also contribute to the over-prediction of the events by increased anomalous upwelling. Especially, the particular cyclonic winds in the ASO season may induce the largest error growth of PDO-related SSTA in the ASO season. However, for warm events, an anticyclonic wind occurs over the North Pacific in summer and early autumn. The southeasterly along the PDO-related SSTA region leads to anomalous absorption of latent heat flux. Moreover, the anticyclonic wind stress favors the downwelling of waters. Thus, a large positive prediction error of the PDO-related SST warm events occurs in the ASO season and makes the warm events to be over-estimated; furthermore, it grows most rapidly in the ASO season due to the particular anticyclonic wind in this season (Fig. 14b, c).

\subsection{Dynamics}

The contributions of oceanic dynamical processes to the error growth for the PDO-related SST warm and cold events can be estimated by Eq. (4). Figure 15 shows the details, which are measured by the norm $A=\sqrt{\sum_{i, j} A_{i j}^{2}}$ $\left[A_{i j}\right.$ denotes the oceanic temperature advection error at each grid point $(i, j)$ in the PDO-related SSTA region]. It is shown that, for either warm or cold events, the contribution of the climatological vertical temperature advection $\bar{W}$ is significantly larger than that of other kinds of temperature advections during the ASO season. In other words, the contribution of the climatological vertical temperature advection may dominate those of temperature advections to the growth of prediction errors for the PDO-related SSTA in the ASO season. 

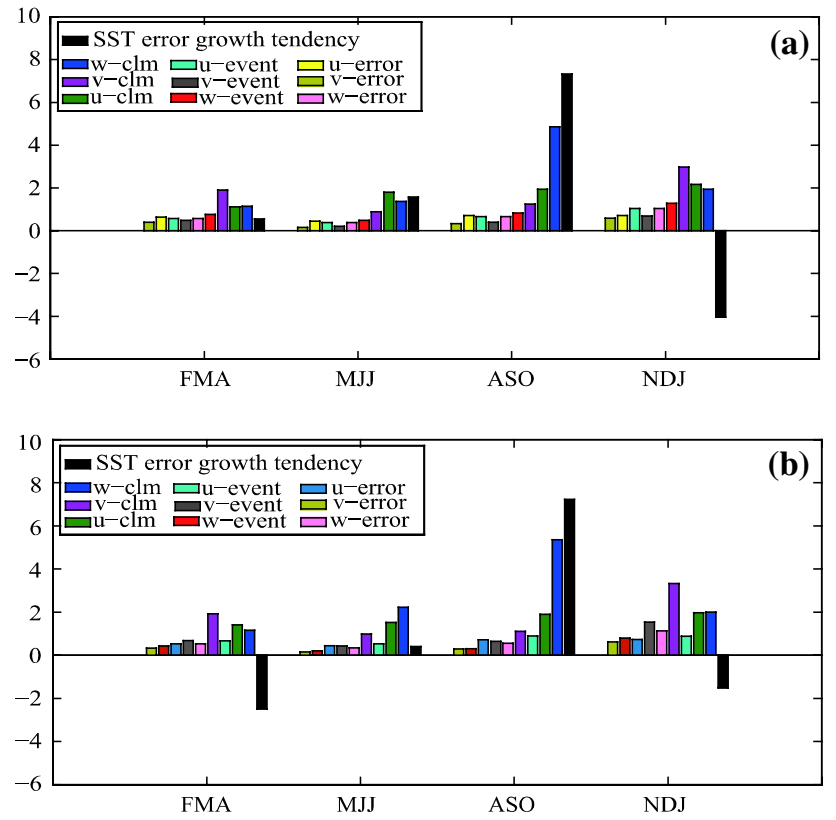

Fig. 15 Error growth tendencies of the PDO-related SST a cold and b warm events in each season (black bars) and their related oceanic temperature advection errors (colored bars; measured by the given norm in Sect. 4.2), which are respectively based on the mean of the 200 predictions for the cold and warm events. The starting month of the predictions is $\mathrm{Feb}(0)$. The $w$-, $v$-, and $u$-clm in each panel represent the effect of the climatological mean state (vertical, meridional, and zonal temperature advections) on the error growth [the first row of Eq. (4)]; w-, v-, and u-event denote the effect of anomalous temperature advection associated with PDO-related SSTA events on the error growth [the second row of Eq. (4)]; and w-, v-, and u-error signify the effect of the temperature advection induced by the initial errors on the error growth (which indicates the effect of nonlinearity) [the third row of Eq. (4)]. Units: K/month

The contribution of climatological vertical temperature advection to the error growth, denoted by $\bar{W}=-w^{\prime} \cdot \partial \bar{T} / \partial z-\bar{w} \cdot \partial T^{\prime} / \partial z$, can be rewritten as $\bar{W}=A+B$, where $A=-w^{\prime} \cdot \partial \bar{T} / \partial z$ and $B=-\bar{w} \cdot \partial T^{\prime} / \partial z$ describe the effect of the vertical gradient of climatological mean sea temperature on the anomalous upwelling (downwelling), and the effect of climatological mean upwelling (downwelling) on the anomalous vertical sea temperature gradient, respectively. In Fig. 16a, we plot the terms $A$ and $B$ for both warm and cold events. It is shown that $A$, similar to the error growth behavior of PDO-related SSTA, also exhibits a season-dependent evolution with the largest evolution in August or September, which indicates that the dynamical process indicated by the term $A$ plays a major role in the effect of climatological vertical temperature advection on the error growth of PDO-related SSTA. In fact, in the term $A$, the vertical gradient of climatological mean sea temperature (indicated by $\partial \bar{T} / \partial z$ ) is largest during the ASO season due to the shallowest mixing-layer depth of the North Pacific occurring in this season (Fig. 16b), which combines

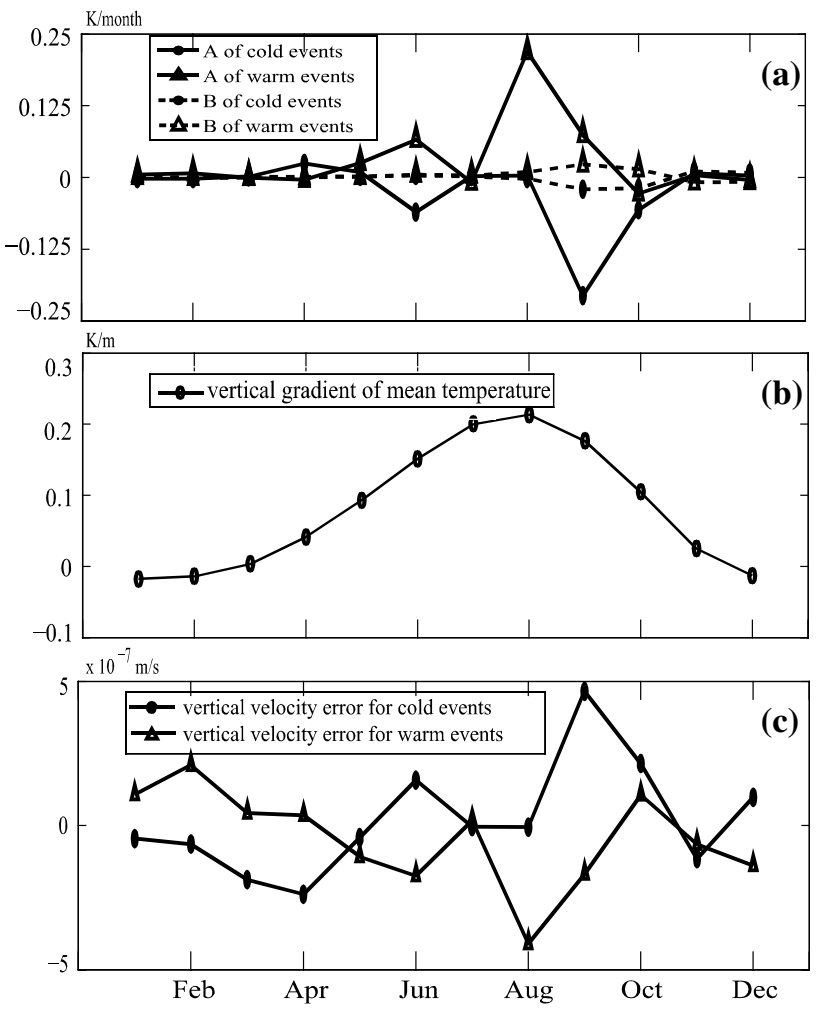

Fig. 16 Time-dependent evolution of a two components $\left(A=-w^{\prime} \cdot \partial \bar{T} / \partial z, B=-\bar{w} \cdot \partial T^{\prime} / \partial z\right)$ of the effect of climatological vertical temperature advection $\left(\bar{W}=-w^{\prime} \cdot \partial \bar{T} / \partial z-\bar{w} \cdot \partial T^{\prime} / \partial z\right)$ (units: K/month); $\mathbf{b}$ the vertical gradient of the climatological mean sea temperatures $(\partial \bar{T} / \partial z)$ in the North Pacific (units: K/m); and $\mathbf{c}$ the vertical velocity errors of ocean currents $\left(w^{\prime}\right)$ (units: $10^{-7} \mathrm{~m} / \mathrm{s}$ ). a, c are calculated based on the mean of the 200 predictions for warm and cold events

the anomalous upwelling component $w^{\prime}$ of the prediction errors superimposed on the cold events (or downwelling of the prediction errors on the warm events; and then enhances the growth of the negative (positive) prediction errors for the PDO-related SST cold (warm) events, ultimately favoring the largest error growth occurring in the ASO season.

From the above analysis, it is demonstrated that the anomalous upwelling or downwelling induced by the initial errors makes a major contribution to the dynamical temperature advections in enhancing the error growth of PDO-related SSTA, although the largest vertical sea temperature gradient in the PDO-related SSTA region in summer induces the seasonality of the error growth of PDOrelated SSTA. The oceanic upwelling or downwelling is closely related to the anomalous wind stress field. Therefore, the error growth of the SPB for PDO-related SSTA is largely contributed to by the effect of the anomalous wind stress field in view of the dynamics. In fact, the anomalous northwesterly (southeasterly) [or cyclonic (anti-cyclonic); see Figs. 13, 14] wind stress component of the prediction errors for cold (warm) events strengthens the upwelling 
Fig. 17 Composite spatial patterns of climatological vertical temperature advection (shaded; units: $\mathrm{K} /$ month) associated with prediction errors of PDO-related SSTA and related wind stress (vectors; units: $\mathrm{N} / \mathrm{m}^{2}$ ) in the FMA, MJJ, ASO and NDJ seasons for the 200 predictions of $\mathbf{a}$ cold and $\mathbf{b}$ warm events. The starting month of the predictions is $\mathrm{Feb}(0)$
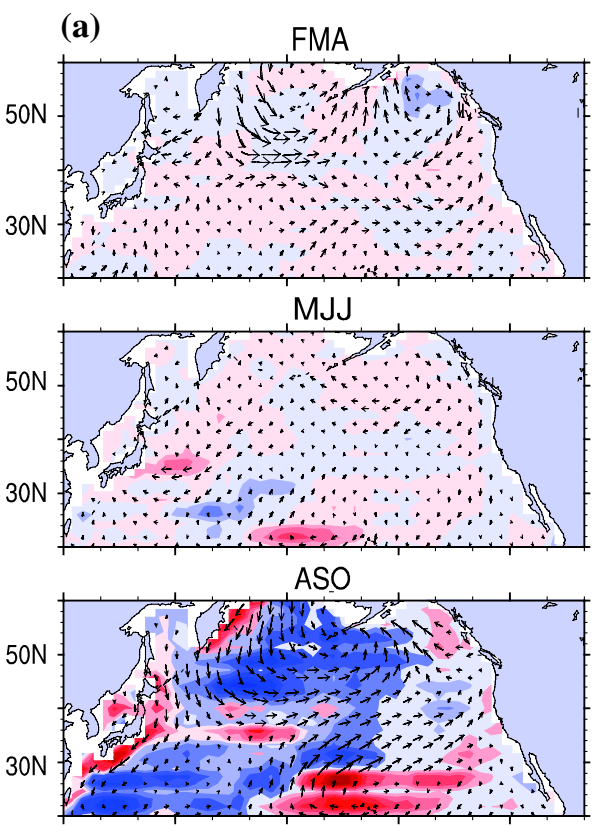

NDJ

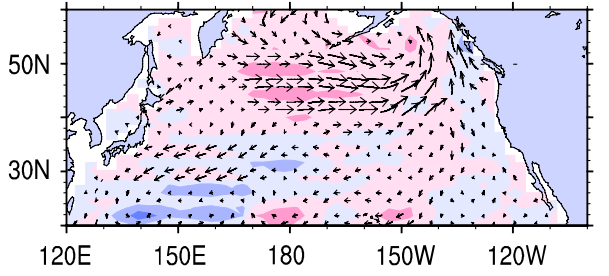

(b)

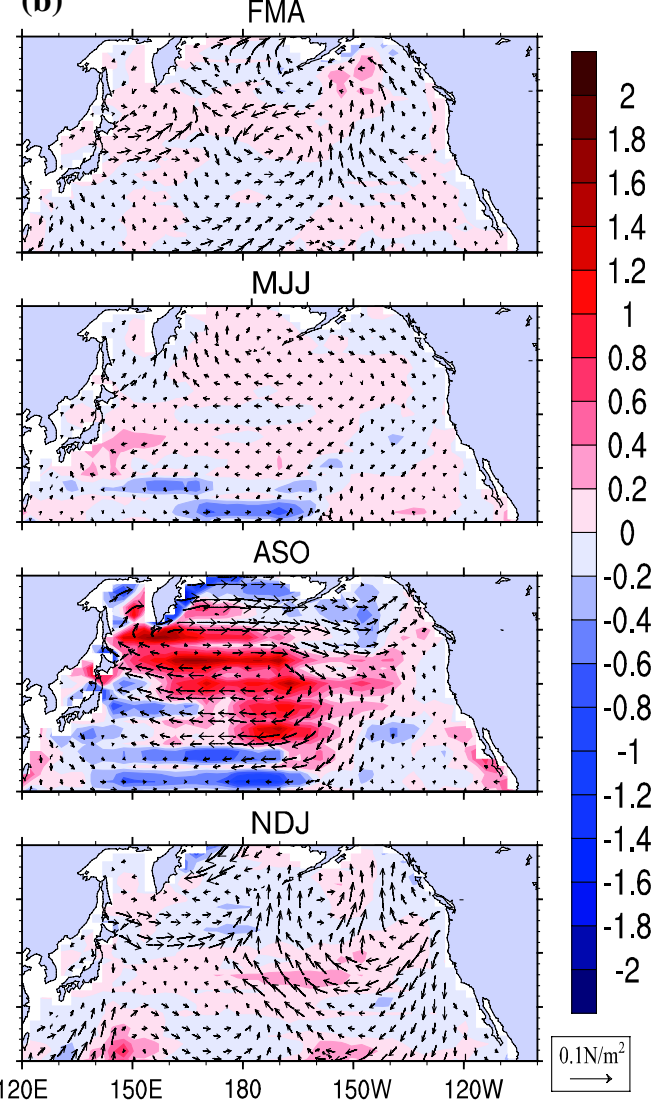

(downwelling) in the PDO-related SSTA region, which, combined with the largest vertical temperature gradient in the North Pacific in summer (see Fig. 17), could most significantly enhance the growth of the negative (positive) prediction errors of PDO-related SSTA in the ASO season.

Meanwhile, we have also demonstrated that, in terms of thermodynamics, the anomalous summer northwesterly (southeasterly) winds associated with the prediction errors for cold (warm) events bring dry and cold (warm and wet) air to the PDO-related SSTA region and enhance the anomalous release (absorption) of net latent heat flux, which is favorable for a negative (positive) prediction error occurring in the PDO-related SSTA region, and significant growth of these errors in the ASO season. Therefore, in terms of both the thermodynamics and dynamics of the error growth, the anomalous wind stress over the PDOrelated SSTA region plays an important role in the error growth associated with the SPB of PDO-related SSTA.

\section{Robustness of the results}

The results presented here have demonstrated that an SPB exists in the predictions of PDO-related SSTA from the viewpoint of initial error growth. We constructed initial errors by using the leading 20 EOF modes of NP-SST anomalies associated with the PDO-related SST warm and cold events and showed the SPB phenomenon of PDOrelated SSTA. We demonstrate that the initial errors that cause a significant SPB make the PDO-related SSTA to be under-predicted during the growing phase of the PDOrelated SST warm (cold) events; and, after that, it grows to be a positive (negative) prediction error with the largest growth in the ASO season and hinder the damping of the events, ultimately delaying the peak of the events. To examine the robustness of the results, we conducted another group of perfect model predictability experiments, in which the initial errors were also extracted from the NP-SST in the model's control run, but exactly described by the difference of the North Pacific sea temperatures between 2 months. In particular, for a PDO-related SST warm or cold event to be predicted, we took the sea temperature field at a month before the starting month of predictions as the initial analysis field, which was clearly different from the sea temperature field of the reference state PDO-related SSTA event at the starting month. We normalized the difference between these two sea temperature fields to a reasonable magnitude (i.e., $\sigma=5$ ) by the approach described in Sect. 2 and regarded it as an initial error used in the predictability experiments, where the initial errors, as described 
Fig. 18 The prediction error variances of PDO-related SSTA normalized by the signal variances and related four heat fluxes and nine dynamical terms in Eq. (4). The w-, v-, u-clm, w-, v-, u-event and w-, v-, u-error are the same as those in Fig. 15, but represent the error variance normalized by the counter part of the signal variance

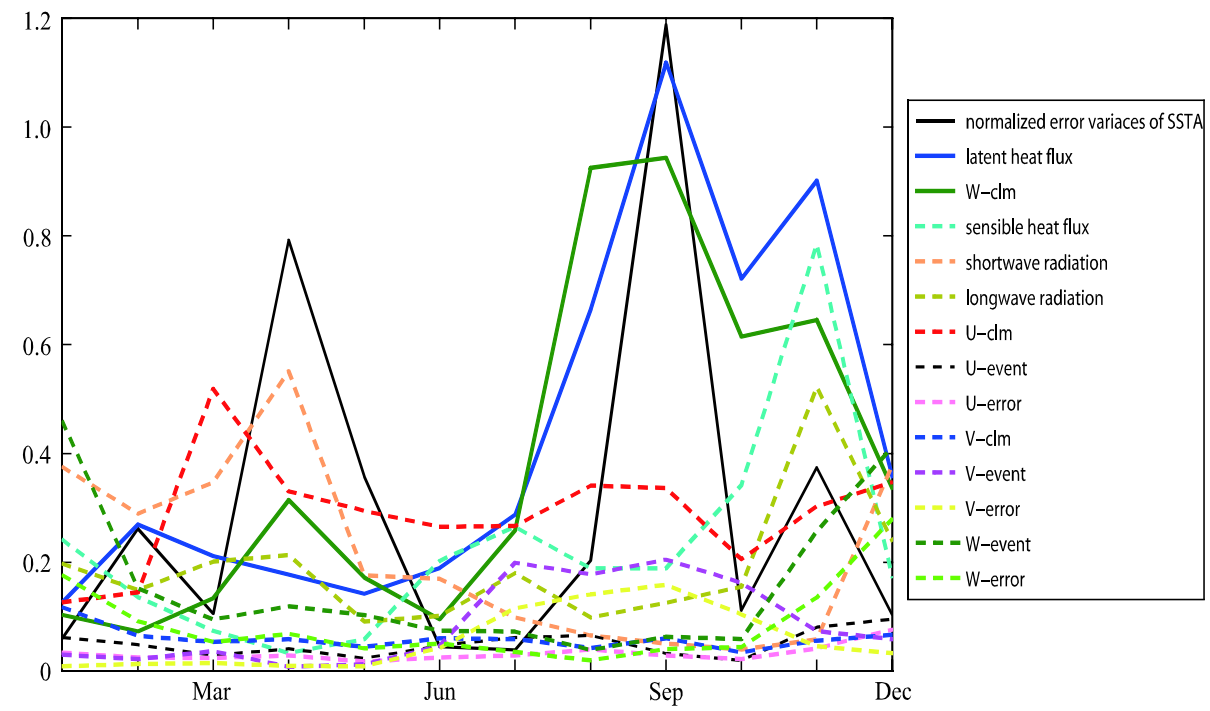

in Sect. 2, have magnitudes being about 30-50\% of initial anomalies of the PDO-related SSTA events. Considering that the period of the PDO-related SSTA warm-cold cycle is about 3 years, for each starting month of the predictions, we chose the sea temperature field in each month of the continuous 36 months before the starting month as initial analysis field and constructed 36 initial errors with the magnitude $\sigma=5$ to predict the corresponding PDO-related SSTA events, respectively. In this group of experiments, we obtained similar results to those reported in Sects. 3 and 4. That is, the largest error growth of PDO-related SST warm and cold events often occurs in the ASO season, indicating that the predictions of PDO-related SSTA may be much more likely to yield the SPB phenomenon; furthermore, the initial errors that yield a significant SPB often cause the PDO-related SSTA to be under-predicted during the growing phase of the corresponding events; while they, due to the fastest growth of these initial errors in the ASO season, usually cause a positive prediction error for the PDOrelated SST warm events but a negative prediction error for the PDO-related SST cold events at the prediction time (exactly after the peak phase of the events), ultimately hindering the damping of the events and delaying the peak of the events. For simplicity, we do not show the details here. These results help to validate the SPB phenomenon for the PDO-related SST warm and cold events and demonstrate the robustness of the results presented in Sects. 3 and 4.

In this study, the SPB of PDO-related SST warm and cold event was revealed by tracing the evolutions of prediction errors caused by initial errors. In the numerical experiments, the SPB was also confirmed by a signal-to-noiseratio-like measurement, which is defined by a ratio of the prediction error variance normalized by the signal variance (the signal variance is referred to as the variance of SSTA associated with the warm and cold events) and measures the relative growth of prediction errors against the PDOrelated SSTA. In Fig. 18, we plot this ratio as a function of time. It is shown that the largest prediction error variance normalized by the signal variance occurs in September with the ratio exceeding 1.0, which suggests that the prediction errors are much more likely to conceal the signal in this month, and the predictions of the warm and cold events tend to be more unsuccessful bestriding this month, being most likely to cause an SPB. The signal-to-noise-ratio-like measurement is a statistical one. Despite the greater likelihood of the predictions being unsuccessful when bestriding this month, it does not mean that the predictions of PDOrelated SSTA in ASO season are always unsuccessful. In our experiments, we found that some of the initial errors lead to a significant SPB but others fail to do despite the existence of seasonality of the climatological annual cycle. We can also see from Fig. 18 that the net latent heat flux and climatological vertical temperature advection almost dominate the prediction error variance normalized by the signal variance, which implies the net latent heat flux and climatological vertical temperature advection both play major roles in the error growth of the PDO-related SSTA events. These results are in accordance with those reported in Sects. 3 and 4, further emphasizing the robustness of the findings obtained in this study.

\section{Summary and discussion}

In this paper, the "summer prediction barrier" (SPB) of PDO-related SST warm and cold events has been revealed from the viewpoint of initial error growth. Perfect model predictability experiments were conducted for typical PDO-related SSTA events including 10 warm and 10 cold ones. The 20 initial sea temperature errors, which 
were obtained by applying EOF and linear regression to the NP-SST anomalies and being scaled to have the same amplitude, were superimposed on the initial field of each PDO-related SST warm and cold event, finally obtaining 20 members of predictions for each of starting months $\operatorname{Nov}(-1), \operatorname{Feb}(0), \operatorname{May}(0)$ and $\operatorname{Aug}(0)$. By investigating the growth tendencies of prediction errors in different seasons, the phenomenon that initial errors exhibit a significant season-dependent evolution with the largest error growth occurring in the ASO season is revealed as the SPB of PDO-related SSTA events. Due to the effect of the SPB, the prediction error of PDO-related SSTA events starts to grow rapidly during the ASO season and yields a positive (negative) prediction error for the warm (cold) events, essentially inducing a delay of the events. The possible mechanism of the error growth associated with the SPB is explored, and it is found that the error growth is mainly due to the net sea surface heat flux and oceanic temperature advections.

For the net sea surface heat flux component, we demonstrated that the net latent heat flux errors exhibit a significant season-dependent evolution, with the largest error growth occurring in the ASO season, almost dominating the net sea surface heat flux component of the prediction errors for PDO-related SSTA. In particular, the SPB-related SSTA error growth for warm events is mainly due to the anomalous absorption of the latent heat flux induced by the anomalous southeasterly wind over the PDO-related SSTA region, while that of cold events is mainly caused by the anomalous latent heat flux release induced by the anomalous northwesterly wind. It is indicated that the anomalous wind stress errors play an important role in the growth of latent heat flux error in the ASO season. In addition, we found that the climatological mean state and the predetermined reference state warm or cold events themselves also play major roles in enhancing the error growth associated with the SPB of PDO-related SSTA. Specifically, the weakest climatological surface wind stress over the North Pacific in summer is most favorable for the fast growth of PDO-related SSTA errors due to the weakest forcing effect of the summer climatological winds on the NP-SST. And the anomalous summer northwesterly (southeasterly) winds associated with the predetermined cold (warm) events also increase the anomalous release (absorption) of net latent heat flux and enhance the error growth of PDO-related SSTA.

In terms of the effect of dynamical oceanic temperature advection on the growth of prediction errors for the PDOrelated SSTA, we found that the effect of the vertical gradient of climatological mean sea temperature on the anomalous upwelling or downwelling plays an important role in the error growth of the PDO-related SSTA. In particular, the largest vertical sea temperature gradient in the PDOrelated SSTA region in summer, together with anomalous upwelling (downwelling) induced by the anomalous summer cyclonic (anti-cyclonic) wind stress errors, aggressively increases the prediction errors of the PDO-related SST cold (warm) events over the PDO-related SSTA region and favors the largest error growth occurring in the ASO season.

Clearly, for either the oceanic thermodynamical or dynamical mechanisms associated with the error growth for the SPB of the PDO-related SSTA, the anomalous wind stress over the PDO-related SSTA region plays an important role in the error growth associated with the SPB of PDO-related SSTA. That is to say, the evolution of the initial errors superimposed on the PDO-related SSTA may be mainly driven by the anomalous wind stress; and the weakest climatological wind stress over the PDO-related SSTA region in summer, as well as the largest vertical sea temperature gradient in the North Pacific in summer, is favorable for the error growth being season-dependent.

We noted from Figs. 13c, 14c that, in terms of the evolution of the prediction errors of NP-SST, the most significant error growth mainly occurs over the PDO-related SSTA region. That is to say, the PDO-related SSTA region shows more considerable error growth compared to other regions, indicating that it is hard to predict the PDO-related SSTA successfully. Indeed, Alexander et al. (2008), Wen et al. (2012), among others, used state-of-the-art models to demonstrate that the PDO-related SSTA is predicted for lead times of barely longer than one season. That is to say, the PDO-related SSTA may be much less predictable compared to the SSTA in other regions of the North Pacific. Therefore, the results reported in the present paper may provide a physically based explanation of the low predictability of PDO-related SSTA.

The above results were derived from the viewpoint of error growth. As mentioned, we also used a signal-tonoise-like measurement to estimate the predictability in the numerical experiments and confirmed the results associated with the SPB for PDO-related SST warm and cold events. In particular, we demonstrated that some initial errors cause a significant SPB, while others fail to cause an SPB. Which features, then, display the spatial patterns of initial errors associated with the SPB? Despite using a similar approach to that of Duan et al. (2009) for identifying the spatial characteristics of the initial errors that cause a significant "spring prediction barrier" for El Niño events, it may be challenge to determine the common characteristics of initial errors that cause a significant SPB for PDO-related SSTA events due to the effect of complicated multi-scale phenomena. Nevertheless, the initial error that is most likely to cause a significant SPB should be possible to determine. Unfortunately, the statistical approach used here may not provide sufficient information for us to explore this problem. One major reason for this is that, although different strategies have been applied to obtain the 
initial errors, they may not guarantee that the chosen initial errors contain all the different kinds of initial error patterns, and ultimately may not be able to identify the particular initial errors that are most likely to cause a significant SPB for PDO-related SSTA events. Therefore, it is necessary to explore this problem by some other advanced dynamical methods, such as the conditional nonlinear optimal perturbation (CNOP; Mu et al., 2003), which represents the initial errors that have the largest effect on the prediction uncertainties and has been successfully applied to explore the characteristics of the initial errors that are most likely to cause a significant "spring predictability barrier" for ENSO (Mu et al., 2007a, 2007b; Yu et al., 2009, 2012). In addition, Yu et al. (2009) showed that random initial errors cannot yield a significant "spring prediction barrier" for El Niño events. ENSO is a strong ocean-atmosphere coupling phenomenon, while the PDO-related SST warm and cold events, as mentioned above, are mainly derived by atmospheric wind forcing. Therefore, PDO-related SST warm and cold events are significantly different from ENSO, and so we naturally question whether random initial errors cannot cause an SPB for PDO-related SSTA events. In summary, concerning the roles of initial errors in the error growth associated with SPB, there are still questions to be addressed. This encourages us to explore the characteristics of initial errors associated with SPB in future work, in an attempt to provide useful information for improving the forecast skill of PDO-related SST warm and cold events.

In addition, the marked effect of surface wind stress on the error growth associated with the SPB of PDO-related SSTA indicates the importance of extratropical oceanatmosphere feedback in understanding the mechanism responsible for the seasonal to interdecadal variability of the North Pacific. In this paper, we have not explained how the anomalous wind stress is induced by the SSTA initial errors, which is related to the problem of how the atmosphere responds to extratropical SST. Although observational and modeling studies have provided some evidence for an atmospheric response to extratropical SST variability (e.g., Sutton and Hodson 2005; Delworth et al. 2007; Liu et al. 2007), the issue remains debatable (Liu 2012). In summary, there are many unresolved issues in studies of the predictability of NP-SST. However, as more coupled general circulation models and advanced methods become available, greater insights into addressing these issues are likely in the future.

Acknowledgments We wish to thank the anonymous reviewers for their insightful comments and constructive suggestions. This work was jointly sponsored by the National Basic Research Program of China (Grant No. 2012CB955202), the National Natural Science Foundation of China (Grant No. 41376018), and the Strategic Priority Research Program of the Chinese Academy of Sciences (Grant No. XDA11010303).
Open Access This article is distributed under the terms of the Creative Commons Attribution License which permits any use, distribution, and reproduction in any medium, provided the original author(s) and the source are credited.

\section{References}

Alexander MA, Matrosova L, Penland C, Scott JD, Chang P (2008) Forecasting Pacific SSTs: linear inverse model predictions of the PDO. J Clim 21:385-402

Auad G, Miller AJ, Roads JO (2004) Pacific Ocean forecasts. J Mar Syst 45:75-90

Beattie JC, Elsberry RL (2012) Western North Pacific monsoon depression formation. Weather Forecast 27:1413-1432

Cayan DR (1992a) Latent and sensible heat flux anomalies over the northern oceans: driving the sea surface temperature. J Phys Oceanogr 22:859-879

Cayan DR (1992b) Latent and sensible heat flux anomalies over the northern oceans: the connection to monthly atmospheric circulation. J Clim 5(4):354-369

Delworth T, Zhang R, Mann M (2007) Decadal to centennial variability of the Atlantic from observations and models. Ocean circulation: mechanisms and impacts, Geophys Monogr 173:131-148

Duan WS, Liu X, Zhu KY, Mu M (2009) Exploring initial errors that cause a significant spring predictability barrier for El Niño events. J Geophys Res 114(C04022). doi:10.1029/2008JC004925

Duan WS, Yu Y, Xu H, Zhao P (2013) Behaviors of nonlinearities modulating the El Niño events induced by optimal precursory disturbances. Clim Dyn 40(5-6):1399-1413

Frankignoul C, Sennéchael N (2007) Observed influence of North Pacific SST anomalies on the atmospheric circulation. J Clim 20(3):592-606

Guemas V, Doblas-Reyes FJ, Lienert F, Soufflet Y, Du H (2012) Identifying the causes of the poor decadal climate prediction skill over the North Pacific. J Geophys Res 117:D20111. doi:10.102 9/2012JD018004

Hu ZZ, Huang B (2009) Interferential impact of ENSO and PDO on dry and wet conditions in the U.S. Great Plains. J Clim 22:6047-6065

Hu Z, Yang S, Wu R (2003) Long-term climate variations in China and global warming signals. J Geophys Res 108(D19):4614

Jacob RL (1997) Low frequency variability in a simulated atmosphere-ocean system. Ph.D. thesis, University of Wisconsin-Madison, $\mathrm{p} 155$

Jiang Z, Wang D (2010) A study on precursors to blocking anomalies in climatological flows by using conditional nonlinear optimal perturbations. Q J R Meteorol Soc 136(650):1170-1180

Landman WA, Mason SJ (2001) Forecasts of near-global sea surface temperatures using canonical correlation analysis. J Clim 14(18):3819-3833

Latif M, Barnett TP (1994) Causes of decadal climate variability over the North Pacific and North America. Science 266:634-637

Latif M, Barnett TP (1996) Decadal climate variability over the North Pacific and North America: dynamics and predictability. J Clim 9:2407-2423

Lau KM, Yang S (1996) The Asian monsoon and predictability of the tropical ocean-atmosphere system. Q J R Meteorol Soc 122:945-957

Lau KM, Lee JY, Kim KM, Kang IS (2004) The North Pacific as a regulator of summertime climate over Eurasia and North America. J Clim 17:819-833

Liu Z (2012) Dynamics of interdecadal climate variability: a historical perspective. J Clim 25(6):1963-1995 
Liu Z, Wu L (2004) Atmospheric response to the North Pacific SST: the role of ocean-atmosphere coupling. J Clim 17:1859-1882

Liu Z, Otto-Bliesner B, Kutzbach J, Li L, Shields C (2003) Coupled climate simulation of the evolution of global monsoons in the holocene. J Clim 16(15):2472-2490

Liu Z, Liu Y, Wu L, Jacob R (2007) Seasonal and long-term atmospheric responses to reemerging North Pacific ocean variability: a combined dynamical and statistical assessment. J Climate 20:955-980

Lorenz EN (1975) Climate predictability: The physical basis of climate modelling. Global Atmosphere Research Programme publication series vol 16, pp132-136, World Meteorological Organisation, Geneva

Mantua NJ, Hare SR, Zhang Y, Wallace JM, Francis RC (1997) A Pacific interdecadal climate oscillation with impacts on salmon production. Bull Am Meteorol Soc 78:1069-1079

McPhaden MJ (2003) Tropical Pacific Ocean heat content variations and ENSO persistence barriers. Geophys Res Lett 30(9):1480

Moore AM, Kleeman R (1996) The dynamics of error growth and predictability in a coupled model of ENSO. QJR Meteorol Soc 122:1405-1446

Motokawa N, Matsuo N, Iwasaka N (2010) Dominant sea-surface temperature anomaly patterns in summer over the North Pacific Ocean. J Oceanogr 66:581-590

Mu M, Duan WS, Wang B (2003) Conditional nonlinear optimal perturbation and its applications. Nonlinear Process Geophys 10:493-501

Mu M, Duan WS, Wang B (2007a) Season-dependent dynamics of nonlinear optimal error growth and El Niño-Southern oscillation predictability in a theoretical model. J Geophys Res Atmos (1984-2012):112(D10)

Mu M, Xu H, Duan WS (2007b) A kind of initial errors related to "spring predictability barrier" for El Niño events in Zebiak-Cane model. Geophys Res Lett 34:L03709

Newman M (2007) Interannual to decadal predictability of tropical and North Pacific sea surface temperatures. J Clim 20:2333-2356

Saha $S$ et al (2006) The NCEP climate forecast system. J Clim 19:3483-3517

Samelson RG, Tziperman E (2001) Instability of the chaotic ENSO: the growth-phase predictability barrier. J Atmos Sci 58:3613-3625

Schneider N, Cornuelle BD (2005) The forcing of the Pacific decadal oscillation. J Clim 18:4355-4373
Smith TM, Reynolds RW, Peterson TC et al (2008) Improvements to NOAA's historical merged land-ocean surface temperature analysis (1880-2006). J Clim 21:2283-2296

Sutton R, Hodson D (2005) Atlantic Ocean forcing of North American and European summer climate. Science 309:115-118

Vavrus S, Notaro M, Liu Z (2006) A mechanism for abrupt climate change associated with tropical Pacific SSTs. J Clim 19:242-256

Wang H, Kumar A, Wang W, Xue Y (2012a) Seasonality of the Pacific decadal oscillation. J Clim 25(1):25

Wang Q, Mu M, Dijkstra HA (2012b) Application of the conditional nonlinear optimal perturbation method to the predictability study of the Kuroshio large meander. Adv Atmos Sci 29(1):118-134

Webster P (1995) The annual cycle and the predictability of the tropical coupled ocean-atmosphere system. Meteorol Atmos Phys 56(1-2):33-55

Webster PJ, Yang S (1992) Monsoon and ENSO: selectively interactive systems. Q J R Meteorol Soc 118:877-926

Wen CH, Xue Y, Kumar A (2012) Seasonal prediction of North Pacific SSTs and PDO in the NCEP CFS hindcasts. J Clim 25:5689-5710

Yang H, Liu Z (2005) Tropical-extratropical climate interaction as revealed in idealized coupled climate model experiments. Clim Dyn 24(7-8):863-879

Yatagai A, Yasunari T (1994) Trends and decadal-scale fluctuations of surface air temperature and precipitation over China and Mongolia during the recent 40 year period (1951-1990). J MetabSocJpn 72:937-957

Yu R, Zhou T (2007) Seasonality and three-dimensional structure of the interdecadal change in East Asian monsoon. J Climate 20:5344-5355

Yu Y, Duan WS, Mu M (2009) Dynamics of nonlinear error growth and season-dependent predictability of El Niño events in the Zebiak-Cane model. QJR Meteorol Soc 135:2146-2160

Zhang Y, Wallace JM, Battisti DS (1997) ENSO-like interdecadal variability: 1900-93. J Clim 10:1004-1020

Zhang XH, Yu YQ, Liu H (1998) Wintertime North Pacific surface heat flux anomaly and air-sea interaction in a coupled oceanatmosphere model. Sci Atmos Sin 22(4):511-521

Zhao X, Li JP, Zhang WJ (2012) Summer persistence barrier of sea surface temperature anomalies in the central western North Pacific. Adv Atmos Sci 29(6):1159 